\title{
A size-composition resolved aerosol model for simulating the dynamics of externally mixed particles: SCRAM (v 1.0)
}

\author{
S. Zhu, K. N. Sartelet, and C. Seigneur \\ CEREA, joint laboratory Ecole des Ponts ParisTech - EDF R\&D, Université Paris-Est, 77455 Champs-sur-Marne, France \\ Correspondence to: S. Zhu (zhus@cerea.enpc.fr)
}

Received: 17 October 2014 - Published in Geosci. Model Dev. Discuss.: 20 November 2014

Revised: 30 April 2015 - Accepted: 5 May 2015 - Published: 1 June 2015

\begin{abstract}
The Size-Composition Resolved Aerosol Model (SCRAM) for simulating the dynamics of externally mixed atmospheric particles is presented. This new model classifies aerosols by both composition and size, based on a comprehensive combination of all chemical species and their mass-fraction sections. All three main processes involved in aerosol dynamics (coagulation, condensation/evaporation and nucleation) are included. The model is first validated by comparison with a reference solution and with results of simulations using internally mixed particles. The degree of mixing of particles is investigated in a box model simulation using data representative of air pollution in Greater Paris. The relative influence on the mixing state of the different aerosol processes (condensation/evaporation, coagulation) and of the algorithm used to model condensation/evaporation (bulk equilibrium, dynamic) is studied.
\end{abstract}

\section{Introduction}

Increasing attention is being paid to atmospheric particulate matter (PM), which is a major contributor to air pollution issues ranging from adverse health effects to visibility impairment (EPA, 2009; Pascal et al., 2013). Concentrations of $\mathrm{PM}_{2.5}$ and $\mathrm{PM}_{10}$ are regulated in many countries, especially in North America and Europe. For example, regulatory concentration thresholds of 12 and $20 \mu \mathrm{g} \mathrm{m}^{-3}$ have been set for $\mathrm{PM}_{2.5}$ annual mass concentrations in the United States and Europe, respectively. Furthermore, particles influence the Earth's energy balance and global climate change (Myhre et al., 2013).

Three-dimensional chemical-transport models (CTM) are often used to study and forecast the formation and distribu- tion of PM. The size distribution of particles is often discretised into sections (e.g. Gelbard and Seinfeld, 1980; Zhang et al., 2004; Sartelet et al., 2007) or approximated by lognormal modes (e.g. Whitby and McMurry, 1997; Binkowski and Roselle, 2003). Moreover, CTM usually assume that particles are internally mixed, i.e. each size section or lognormal mode has the same chemical composition, which may vary in space and time.

The internal-mixing assumption implies that particles of the same diameter (or in the same size section or log-normal mode) but originating from different sources have undergone sufficient mixing to achieve a common chemical composition for a given model grid cell and time. Although this assumption may be realistic far from emission sources, it may not be valid close to emission sources where the composition of new emitted particles can be very different from either background particles or particles from other sources. Usually, internally and externally mixed particles are not differentiated in most measurements, which may be size-resolved (e.g. cascade impactors) but not particle specific (McMurry, 2000). The use of mass spectrometers for individual particle analysis has shed valuable information on the chemical composition of individual particles. Consequently, there is a growing body of observations indicating that particles are mostly externally mixed (e.g. Hughes et al., 2000; Mallet et al., 2004; Healy et al., 2012; Deboudt et al., 2010).

The mixing state assumption may strongly influence aerosol chemistry and the hygroscopic characteristics of particles. Particles from different origins may not be well mixed, and their chemical composition may vary with their origins, leading to variations in their hygroscopic characteristics. This chemical identity of particles is gradually lost as the degree of mixing increases (or completely lost under 
the internal mixing assumption). By influencing the hygroscopic characteristics of particles, the mixing state also influences the formation of secondary organic aerosols (SOA), because condensation/evaporation differs for species that are hydrophilic and/or hydrophobic (Couvidat et al., 2012). As the particle wet diameter is strongly related to the hygroscopic properties of particles, the mixing state also impacts particle wet diameters and the number of particles that become cloud condensation nuclei $(\mathrm{CCN})$, because the activation of particles into $\mathrm{CCN}$ is strongly related to the particle wet diameter (Leck and Svensson, 2015). By influencing $\mathrm{CCN}$, the mixing state also affects aerosol wet removal and thus the aerosol spatial/temporal distribution. Besides, the mixing state influences the particle optical properties, which depend on both the particle size distribution (wet diameters) and composition (different chemical species possess different absorption/scattering properties). Lesins et al. (2002) found that the percentage difference in the optical properties between an internal mixture and external mixture of black carbon and ammonium sulfate can be over $50 \%$ for wet aerosols. The mixing state may also influence radiative forcing, as shown by Jacobson (2001), who obtained different direct forcing results between external and internal mixing simulations of black carbon.

Although CTM usually assume that particles are internally mixed, several models have been developed during the last sesquidecade to represent the external mixture of particles. A source-oriented model was developed by Kleeman et al. (1997) and Kleeman and Cass (2001) for regional modelling. In these models, each source is associated with a specific aerosol population, which may evolve in terms of size distribution and chemical composition, but does not mix with the other sources (i.e. particle coagulation is neglected). Riemer et al. (2009) modelled externally mixed particles using a stochastic approach. However, such an approach is computationally expensive when the number of particle species is high. On the other hand, Stier et al. (2005) and Bauer et al. (2008) simulate externally mixed particles using modal aerosol models, where aerosol populations with different mixing states are represented by modes of different compositions (soluble/mixed or insoluble/not mixed). Although these models may be computationally efficient, they may not model accurately the dynamics of mixing. To represent externally mixed particles independently of their sources and number concentrations, Jacobson et al. (1994) and $\mathrm{Lu}$ and Bowman (2010) considered particles that can be either internally or externally mixed (i.e. composed of a pure chemical species). Lu and Bowman (2010) used a threshold mass fraction to define whether the species is of significant concentration. Jacobson (2002) expanded on Jacobson et al. (1994) by allowing particles to have different mass fractions. Similarly, Oshima et al. (2009) discretised the fraction of black carbon in the total particle mass into sections of different chemical compositions. Dergaoui et al. (2013) further expanded on these modelling approaches by discretising the mass frac- tion of any chemical species into sections, as well as the size distribution (see Sect. 2.1.3 for details). Based on this discretisation, Dergaoui et al. (2013) derived the equation for coagulation and validated their model by comparing the results obtained for internal and external mixing, as well as by comparing both approaches against an exact solution. However, processes such as condensation/evaporation and nucleation were not modelled.

This work presents the new Size-Composition Resolved Aerosol Model (SCRAM), which expands on the model of Dergaoui et al. (2013) by including condensation/evaporation and nucleation processes. Section 2 describes the model. Equations for the dynamic evolution of particles by condensation/evaporation are derived. A thermodynamic equilibrium method may be used in SCRAM to compute the evolution of the particle chemical composition by condensation/evaporation. Redistribution algorithms, which allow section bounds not to vary, are also presented for future 3-D applications. Model validation is presented in Sect. 3 by comparing the changes in the particle size distribution due to condensational growth for both externally and internally mixed particles. Section 4 presents an application of the model with realistic concentrations over Greater Paris.

\section{Model description}

This section presents the aerosol general dynamic equations and the structure of the model. First, the formulation of the dynamic evolution of the aerosol size distribution and chemical composition by condensation-evaporation is introduced. Since it is necessary in 3-D CTM to maintain fixed size and composition section bounds, we present algorithms to redistribute particle mass and number according to fixed section bounds. For computational efficiency, a bulk equilibrium method, which assumes an instantaneous equilibrium between the gas and particle phases, is introduced. Finally, the overall structure of the model is described. In particular, the treatment of the different mixing processes to ensure the numerical stability of the model is discussed.

Particle dynamics is mostly governed by three processes: coagulation, condensation/evaporation, and nucleation. $\mathrm{Nu}-$ cleation refers to the formation of ultra-fine particles from gaseous molecules. SCRAM uses the parametrisation of Vehkamäki et al. (2002) for the homogeneous binary nucleation of sulfate and water. It was adopted from the existing SIREAM code (Debry et al., 2007). It may be replaced by a better parametrisation in future versions, because it may lead to unrealistic results under some extreme conditions (Zhang et al., 2010). For coagulation, SCRAM uses the code of Dergaoui et al. (2013) to simulate the collisions of particles caused by Brownian motion. Condensation/evaporation describe the mass transfer process between the gas and particle phases. It is essential to include condensation/evaporation, 
because this process not only largely influences the size distribution of aerosols, but may also change the composition of particles significantly.

\subsection{Condensation-evaporation algorithm}

The focus of the following subsections is the formulation and implementation of the condensation/evaporation process. A Lagrangian approach is used to solve the equations of change for the mass and number concentrations, which are redistributed onto fixed sections through a redistribution algorithm (moving diameter, Jacobson, 1997). Equations are derived to describe the change with time of the mass concentrations of chemical species in terms of particle compositions.

\subsubsection{Dynamic equation for condensation/evaporation}

Let us denote $m_{i}$ the mass concentration of species $X_{i}(1 \leq$ $i \leq c)$ in a particle and $\boldsymbol{x}$ the vector representing the mass composition of the particle $\boldsymbol{x}=\left(m_{1}, m_{2}, \cdots, m_{c}\right)$. Following Riemer et al. (2009), the change with time of the number concentration $n(\boldsymbol{x}, t)\left(\mathrm{m}^{-3} \mu \mathrm{g}^{-1}\right)$ of multi-species particles by condensation/evaporation can be represented by the following equation:

$$
\frac{\partial n}{\partial t}=-\sum_{i=1}^{c} \frac{\partial\left(I_{i} n\right)}{\partial m_{i}},
$$

where $I_{i}\left(\mu \mathrm{g} \mathrm{s}^{-1}\right)$ is the mass transfer rate between the gas and particle phases for species $X_{i}$. It may be written as follows:

$$
\begin{aligned}
I_{i}=\frac{\partial m_{i}}{\partial t}= & 2 \pi D_{i}^{\mathrm{g}} d_{\mathrm{p}} f\left(K_{n}, \alpha_{i}\right)\left(c_{i}^{\mathrm{g}}(t)\right. \\
& \left.-K_{\mathrm{e}}\left(d_{\mathrm{p}}\right) c_{i}^{\mathrm{eq}}(\boldsymbol{x}, t)\right),
\end{aligned}
$$

where $D_{i}^{\mathrm{g}}$ is the molecular diffusivity of condensing/evaporating species in the air, and $d_{\mathrm{p}}$ and $c_{i}^{\mathrm{g}}$ are the particle wet diameter and the gas-phase concentration of species $X_{i}$, respectively. Non-continuous effects are described by $f\left(K_{n}, \alpha_{i}\right)$ (Dahneke, 1983), which depends on the Knudsen number, $K_{n}=\frac{2 \lambda}{d_{\mathrm{p}}}$ (with $\lambda$ the air mean free path), and on the accommodation coefficient $\alpha_{i}=0.5$ :

$f\left(K_{n}, \alpha_{i}\right)=\frac{1+K_{n}}{1+2 K_{n}\left(1+K_{n}\right) / \alpha_{i}}$.

$K_{\mathrm{e}}\left(d_{\mathrm{p}}\right)$ represents the Kelvin effect (for ultra-fine particles, the curvature tends to inhibit condensation):

$K_{\mathrm{e}}\left(d_{\mathrm{p}}\right)=\exp \left(\frac{4 \sigma v_{\mathrm{p}}}{R T d_{\mathrm{p}}}\right)$,

with $R$ the ideal gas constant, $\sigma$ the particle surface tension and $v_{\mathrm{p}}$ the particle molar volume. The local equilibrium gas concentration $c_{i}^{\text {eq }}$ is computed using the reverse mode of the ISORROPIA V1.7 thermodynamic model
(Nenes et al., 1998) for inorganic compounds. In the current version of SCRAM, organic compounds are assumed to be at thermodynamic equilibrium with the gas phase and condensation/evaporation is computed as described in Sect. 2.2.

\subsubsection{Dynamic equation as a function of mass fractions}

Following the composition discretisation method of Dergaoui et al. (2013) (detailed in Sect. 2.1.3), each particle is represented by a vector $\boldsymbol{p}=(\boldsymbol{f}, m)$, which contains the mass fraction vector $\boldsymbol{f}=\left(f_{1}, f_{2}, \ldots, f_{(c-1)}\right)$ of the first $(c-1)$ species and the total mass $m=\sum_{i=1}^{c} m_{i}$.

In Eq. (1), the chemical composition of particles is described by the vector $\boldsymbol{x}$, which contains the mass concentration of each species. After the change of variable through a $[c \times c]$ Jacobian matrix from $n(\boldsymbol{x}, t)$ to $\bar{n}(\boldsymbol{p}, t)$ (see Appendix A for detail), Eq. (1) becomes

$\frac{\partial \bar{n}}{\partial t}=-\sum_{i=1}^{(c-1)} \frac{\partial\left(H_{i} \bar{n}\right)}{\partial f_{i}}-\frac{\partial\left(I_{0} \bar{n}\right)}{\partial m}$,

with $I_{0}=\sum_{i=1}^{c} I_{i}, H_{i}=\frac{\partial f_{i}}{\partial t}$. As $f_{i}=\frac{m_{i}}{m}$ is the mass fraction of species (or group of species) $X_{i}$, we may write

$H_{i}=\frac{1}{m} \frac{\partial m_{i}}{\partial t}-\frac{m_{i}}{m^{2}} \frac{\partial m}{\partial t}=\frac{I_{i}-f_{i} I_{0}}{m}$.

The change with time of $q_{i}=n m_{i}$, the mass concentration of species $X_{i}$, can be expressed as follows:

$\frac{\partial q_{i}}{\partial t}=\frac{\partial n}{\partial t} m_{i}+\frac{\partial m_{i}}{\partial t} n$.

After the change of variables from $q_{i}(\boldsymbol{x}, t)$ to $\bar{q}_{i}(\boldsymbol{p}, t)$ (see Appendix A), Eq. (7) becomes

$\frac{\partial \bar{q}_{i}}{\partial t}=-m f_{i} \frac{\partial \bar{n}}{\partial t}+\bar{n} I_{i}$.

\subsubsection{Discretisation}

As SCRAM is a size-composition resolved model, both particle size and composition are discretised into sections, while the numbers and bounds of both size and composition sections can be customised by the user. The particle mass distribution $Q\left[m_{\min }, m_{\max }\right]$ is first divided into $N_{b}$ size sections $\left[m_{k}^{-}, m_{k}^{+}\right]\left(k=1, \ldots, N_{b}\right.$ and $\left.m_{k-1}^{+}=m_{k}^{-}\right)$, defined by discretising particle diameters $\left[d_{\min }, d_{\max }\right]$ with $d_{\min }$ and $d_{\max }$, the lower and upper particle diameters, respectively, and $m_{k}=\frac{\pi \rho d_{k}^{3}}{6}$. For each of the first $(c-1)$ species or species groups, the mass fraction is discretised into $N_{\mathrm{f}}$ fraction ranges. The $h$ th fraction range is represented by the range $F_{h-}^{+}=\left[f_{h}^{-}, f_{h}^{+}\right]$where $f_{h-1}^{+}=f_{h}^{-}, f_{\min }=0$ and $f_{\max }=1$. Within each size section $k$, particles are categorised into $N_{\mathrm{p}}$ composition sections, which are defined by the valid combinations of the fraction ranges of the $(c-1)$ species. 
The $g$ th composition section can be represented by $\boldsymbol{P}_{g}=$ $\left(F_{g 1} 1_{-}^{+}, F_{g 2_{-}^{+}}, \ldots, F_{g c-1}{ }_{-}^{+}\right)$. Given the mass fraction discretisation, those composition sections are automatically generated by an iteration on all possible combinations $\left(N_{\mathrm{f}}{ }^{(c-1)}\right)$ of the $(c-1)$ species and $N_{\mathrm{f}}$ fraction ranges. Only the composition sections that satisfy $\sum_{i=1}^{(c-1)} F_{g i}{ }^{-} \leqslant 1$ are kept.

The particle mass distribution is discretised into $\left(N_{b} \times N_{\mathrm{p}}\right)$ sections. Each section $j\left(j=1, \ldots, N_{b} \times N_{c}\right)$ corresponds to a size section $k\left(k=1, \ldots, N_{b}\right)$ and to a composition section $g=\left(g_{1}, \ldots, g_{(c-1)}\right)$ with $g=1, \ldots, N_{\mathrm{p}}, g_{h}=1, \ldots, N_{\mathrm{f}}$ with $h=1, \ldots,(c-1)$. The total concentration $Q_{i}^{j}$ of species $i$ in the $j$ th section can be calculated as follows:

$$
\begin{aligned}
Q_{i}^{j} & \int_{m_{k}^{-}}^{m_{k}^{+}} \int_{f_{g_{1}}^{-}}^{f_{g_{1}}^{+}} \ldots \int_{f_{g_{(c-1)}}^{-}}^{f_{g_{(c-1)}}^{+}} \bar{q}_{i}\left(m, f_{g_{1}}, \ldots, f_{g_{(c-1)}}\right) \\
& \mathrm{d} m \mathrm{~d} f_{g_{1}} \ldots \mathrm{d} f_{g_{(c-1)}} .
\end{aligned}
$$

Similarly, the number concentration $N^{j}$ of the $j$ th section may be written as follows:

$$
N^{j}=\int_{m_{k}^{-}}^{m_{k}^{+} f_{g_{1}}^{+}} \ldots \int_{f_{g_{(c-1)}}^{-}}^{f_{g_{(c-1)}}^{+}} \bar{n}\left(m, f_{g_{1}}, \ldots, f_{g_{(c-1)}}\right)
$$

After a series of derivations (see Appendix B for details), we obtain the time derivation of Eq. (10):

$\frac{\partial N^{j}}{\partial t}=0$,

as well as the time derivation of Eq. (9):

$$
\frac{\partial Q_{i}^{j}}{\partial t}=N^{j} I_{g_{i}}
$$

Thus, in each section, the change with time of number and mass concentrations is given by Eqs. (11) and (12).

\subsubsection{Numerical implementation}

According to Debry and Sportisse (2006), the condensation/evaporation process may have characteristic timescales of different magnitudes, because the range of particle diameters is large. Such a feature induces strong stiffness of the numerical system. As suggested by Debry et al. (2007), the stiff condensation/evaporation equations are solved using the second-order Rosenbrock (ROS2) method (Verwer et al., 1999; Djouad et al., 2002).

In addition, potentially unstable oscillations may occur when a dramatic change of the particle $\mathrm{pH}$ occurs. To address this issue, a species flux electro-neutrality constraint (Pilinis et al., 2000; Debry et al., 2007) is applied in SCRAM to ensure the numerical stability of the system.

\subsubsection{Size and composition redistribution}

By condensation/evaporation, the particles in each size section may grow or shrink. Because the bounds of size sections should be fixed for 3-D applications, it is necessary to redistribute number and mass among the fixed size sections during the simulation after condensation/evaporation. Similarly, the chemical composition also evolves by condensation/evaporation, and an algorithm is needed to identify the particle composition and redistribute it into the correct composition sections.

Two redistribution methods for size sections may be used in SCRAM: the HEMEN (Hybrid of Euler-Mass and EulerNumber) scheme of Devilliers et al. (2013) and the moving diameter scheme of Jacobson (1997). According to Devilliers et al. (2013), both redistribution methods may accurately redistribute mass and number concentrations.

The HEMEN scheme divides particle size sections into two parts: the number is redistributed for sections of mean diameter lower than $100 \mathrm{~nm}$ and mass is redistributed for sections of mean diameter greater than $100 \mathrm{~nm}$. The section mean diameters are kept constant and mass concentrations are diagnosed for sections where number is redistributed, while number concentrations are diagnosed for sections where mass is redistributed. The advantage of this scheme is that it is more accurate for number concentrations over the size range where number concentrations are the highest and more accurate for mass concentrations where mass concentrations are the highest. In SCRAM, the algorithm of Devilliers et al. (2013) was modified to take into account the fact that after condensation/evaporation, the diameter of a section may become larger than the upper bound of the next section. In that case, the mean diameter of the section after condensation/evaporation is used to diagnose in which fixed-diameter sections the redistribution is performed. This feature allows us to use larger time steps for condensation/evaporation before redistribution.

In the moving diameter method, although size section bounds are kept fixed, the representative diameter of each size section is allowed to vary. If, after condensation/evaporation, the diameter grows or shrinks outside section bounds, both the mass and number concentrations of the section are redistributed entirely into the new size sections bounding that diameter.

For the composition redistribution, a scheme based on the moving diameter method is applied (i.e. moving mass fraction). First, after condensation/evaporation, the mass fraction of each species is re-evaluated within each section. For each section, if the new composition does not match the section composition (i.e. if the mass fraction of each species does not fit into the mass fraction bounds of the species for that section), the section that has a composition that matches the new composition is identified, and both the number and mass concentrations of each species are transferred to that section. 
The composition redistribution is applied first, followed by the size redistribution for each of the composition sections.

\subsection{Bulk equilibrium and hybrid approaches}

Bulk equilibrium methods assume an instantaneous thermodynamic equilibrium between the gas and bulkaerosol phases. For semi-volatile species, the mass concentrations of both gas and bulk-aerosol phases after condensation/evaporation are obtained using the forward mode of ISORROPIA for inorganics and the $\mathrm{H}^{2} \mathrm{O}$ model (Couvidat et al., 2012) for organics. Because time integration is not necessary, the computational cost is significantly reduced compared to the dynamic method. Weighting factors $W$ are designed to distribute the semi-volatile bulkaerosol mass across the aerosol distribution (Pandis et al., 1993). In SCRAM, for each semi-volatile species $i$, we redistribute the bulk aerosol evaporating or condensing mass, $\delta Q_{i}=Q_{i}^{\text {after bulk eq. }}-Q_{i}^{\text {before bulk eq. }}$, between the sections $j$, using factors that depend on the ratio of the mass transfer rate in the aerosol distribution (Eq. 2). Because of the bulk equilibrium assumption, the driving force of $\left(c_{i}^{\mathrm{g}}-K_{\mathrm{e}} c_{i}^{\mathrm{eq}}\right)$ is assumed to be the same for all size and composition sections, and the weighting factors are as follows.

$W_{i}^{j}=\frac{N_{j} d_{\mathrm{p}}^{j} f\left(K_{n}, \alpha_{i}\right)}{\sum_{k=1}^{N_{s}} N_{k} d_{\mathrm{p}}^{k} f\left(K_{n}, \alpha_{i}\right)}$,

where $N_{j}$ is the number concentration of section $j$ and $d_{\mathrm{p}}^{j}$ is the particle wet diameter of section $j$. In case of evaporation, these weighting factors may not be appropriate, as they may lead to over-evaporation of some species in some sections, i.e. $Q_{i}^{j}$ after bulk eq. $=Q_{i}^{\text {before bulk eq. }}+\delta Q_{i} \times W_{i}^{j}<0$. In the case of over-evaporation, we use a weighting scheme that redistributes the total bulk aerosol mass rather than the bulk aerosol evaporating or condensing mass

$$
W_{i}^{j}=\frac{Q_{i}^{j}}{\sum_{k=1}^{N_{s}} Q_{i}^{k}}
$$

and $Q_{i}^{j}$ after bulk eq. $=Q_{i}^{\text {after bulk eq. }} \times W_{i}^{j}$.

In fact, due to their larger ratios between surface area and particle mass, small particles may reach thermodynamic equilibrium much faster than large particles. Particles of diameters larger than $1 \mu \mathrm{m}$ could require hours or even days to achieve equilibrium (Wexler and Seinfeld, 1990), which makes the bulk equilibrium assumption inappropriate for them. In order to maintain both the computational efficiency of the equilibrium method and the accuracy of the dynamic one, a hybrid method is adopted in SCRAM based on the work of Capaldo et al. (2000) and Debry and Sportisse (2006). This method uses the equilibrium method for small particles $\left(d_{\mathrm{p}}<1 \mu \mathrm{m}\right)$ and uses the dynamic method to calculate the mass transfer for larger particles.

\subsection{Overall time integration and operator splitting in SCRAM}

In order to develop a system that offers both computational efficiency and numerical stability, we perform operator splitting for changes in number and mass concentrations with time due to emission, coagulation, condensation/evaporation and nucleation, as explained below.

Emissions are first evaluated with an emission time step, which is determined by the characteristic timescales of emissions obtained from the ratio of emission rates to aerosol concentrations. The emission time step evolves with time to prevent adding too much emitted mass to the system within one time step. Within each emission time step, coagulation and condensation/evaporation/nucleation are solved, and the splitting time step between coagulation and condensation/evaporation/nucleation is forced to be lower than the emission time step. Time steps are obtained from the characteristic time steps of coagulation ( $\left.t_{\text {coag }}\right)$ and condensation/evaporation/nucleation $\left(t_{\text {cond }}\right)$. The larger of the time steps $t_{\text {coag }}$ and $t_{\text {cond }}$ determines the time step of splitting between coagulation and condensation/evaporation/nucleation. As coagulation is usually the slower process, the change due to coagulation is first calculated over its time step. Then, condensation/evaporation/nucleation are solved simultaneously. The change due to condensation/evaporation/nucleation is calculated, using time sub cycles, starting with the sub time step $t_{\text {cond }}$. The next sub time step for condensation/evaporation/nucleation is estimated based on the difference between the firstand second-order results provided by the ROS2 solver. Redistribution is computed after each time step of splitting of coagulation and condensation/evaporation/nucleation.

When the bulk thermodynamic equilibrium approach is used to solve condensation/evaporation, coagulation and then nucleation are solved after each emission time step. The resolution is done as previously explained, except that the dynamic condensation/evaporation solver is disabled: sub time steps are used to solve coagulation and nucleation during one emission time step. Condensation/evaporation is then solved using the bulk equilibrium approach and the redistribution process is applied after the bulk equilibrium algorithm.

When the hybrid approach is used to solve condensation/evaporation, a time loop is added with a fixed time step of $600 \mathrm{~s}$ outside the emission time loop to compute bulk equilibrium condensation/evaporation for equilibrium sections. This additional time loop is designed to ensure that bulk equilibrium condensation/evaporation of equilibrium sections is not applied too often, so that the dynamic condensation/evaporation of dynamic sections has time to evolve. Redistribution is applied after the bulk equilibrium algorithm. Within this time loop, the aerosol dynamics is solved as previously explained using the dynamic condensation/evaporation algorithm for dynamic 
size sections: emissions are solved followed by coagulation and condensation/evaporation/nucleation. As in the fully dynamic approach, redistribution is applied after dynamic condensation/evaporation.

\section{Model validation}

To validate the model, the change with time of internally and externally mixed aerosol models is compared. The simulations use initial conditions for number and mass concentrations that are typical of a regional haze scenario, with constant sulfuric acid vapour source that gives a sulfuric acid condensation rate of $5.5 \mu \mathrm{m}^{3} \mathrm{~cm}^{-3}$ per $12 \mathrm{~h}$ (Seigneur et al., 1986; Zhang et al., 1999).

Simulations were conducted for $12 \mathrm{~h}$ at a temperature of $298 \mathrm{~K}$ and a pressure of $1 \mathrm{~atm}$. The original reference simulation (Seigneur et al., 1986; Zhang et al., 1999) was first reproduced for internally mixed sulfate particles (redistribution is not applied). For the sake of comparison between internally and externally mixed simulations, half of the particles were assumed to consist of sulfate (species 1) and the other half of another species of similar physical properties as sulfate (species 2). For internal mixing, the initial particles are all $50 \%$ species 1 and $50 \%$ species 2 ; and for external mixing, half of the initial particles are $100 \%$ species 1 and the other half are $100 \%$ species 2 . As both species have the same physical properties, for any given size section, the sum over all composition sections of number and mass concentrations of externally mixed particles should equal the number and mass concentrations of the internally mixed particles. Particles were discretised into 100 size sections and 10 composition sections for the externally mixed case. Figure 1 shows the initial and final distributions for the number and volume concentrations as a function of particle diameters. Both the internally mixed and externally mixed results are presented in Fig. 1, along with the reference results of Zhang et al. (1999) (500 size sections were used in the original reference simulation). For the externally mixed simulation, the results were summed up over composition sections to obtain the distributions as a function of particle diameter. As expected, an excellent match is obtained between internal and external mixing distributions, with an almost $100 \%$ Pearson's correlation coefficient. Furthermore, the accuracy of the SCRAM algorithm is proved by the excellent match between the results of these simulations and the reference simulation of Zhang et al. (1999). In order to investigate the influence of the composition resolution on simulation results, two additional tests are conducted using 2 and 100 composition bins. The mean mass fraction of species 1 is computed for all particles within each size section, as well as their standard deviations. Figure 2 shows the size distribution of these statistics. The mean mass fraction is barely affected by the different composition resolutions, as the condensation rate of sulfate is independent of the particle compositions. How- ever, a different composition resolution does lead to different standard deviation distributions, as only particles with a larger fraction difference $(d>0.2 \mu \mathrm{m}$ for 2 compositions and $d>0.09 \mu \mathrm{m}$ for 10 compositions) can be distinguished from each other under coarser composition resolutions.

Using the same initial conditions and sulfuric acid condensation rate, a second comparison test was performed, with both coagulation and condensation occurring for $12 \mathrm{~h}$. As the coagulation algorithm requires size sections to have fixed bounds (Dergaoui et al., 2013), size redistribution was applied for both the internally and externally mixed cases using the HEMEN method. As in the first comparison test, Fig. 3 shows that there is an excellent match between the internally and externally mixed distributions as a function of particle diameter (no reference simulation was available for these simulations). This test validates the algorithm of SCRAM to simulate jointly the coagulation and condensation of externally mixed particles.

The mixing states of both internally and externally mixed particles at the end of the simulations of the second test are shown in Fig. 4. Sulfuric acid condenses to form particulate sulfate (species 1). During the simulation, pure species 2 particles mix with pure sulfate particles by coagulation and condensation of sulfuric acid. Figure 4 shows that, at the end of the simulation, the sulfate mass fraction is greater for particles of lower diameters, because the condensation rate is greater for those particles. Particles with diameters greater than $10 \mu \mathrm{m}$ remain unmixed. However, the external mixing state provides a more detailed mixing map, from which it is possible to distinguish mixed particles from unmixed ones and to trace the origin of each particle. In this test case where the effect of condensation dominates that of coagulation, most mixed particles are originally pure species 2 particles coated with newly condensed sulfuric acid (Fig. 4).

\section{Simulation with realistic concentrations}

To test the impact of external mixing on aerosol concentrations, simulations of coagulation, condensation/evaporation and nucleation were performed with SCRAM using realistic ambient concentrations and emissions extracted from a simulation performed over Greater Paris for July 2009 during the MEGAPOLI (Megacities: Emissions, urban, regional and Global Atmospheric POLution and climate effects, and Integrated tools for assessment and mitigation) campaign (Couvidat et al., 2013).

\subsection{Simulation set-up}

Data were extracted from one grid cell of the 3-D simulation performed by Couvidat et al. (2013) over Greater Paris. This surface grid cell was chosen because black carbon (BC) emissions are high in that location, due to high traffic emissions. Figure 5 shows the $\mathrm{BC}$ emission map at 02:00 UT, 


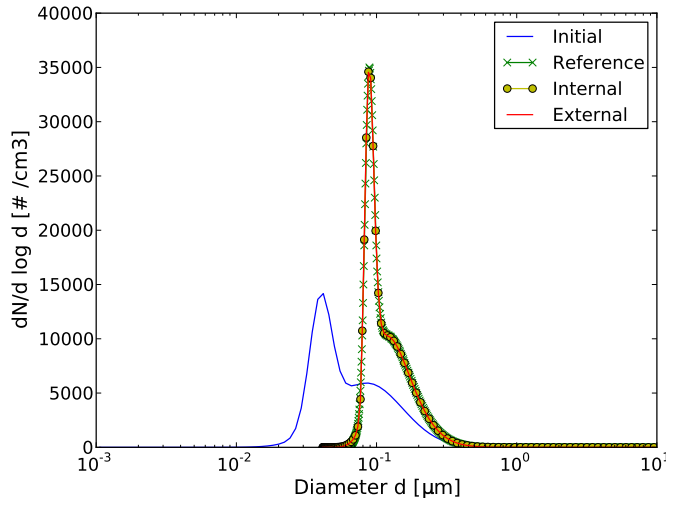

(a) Number distribution

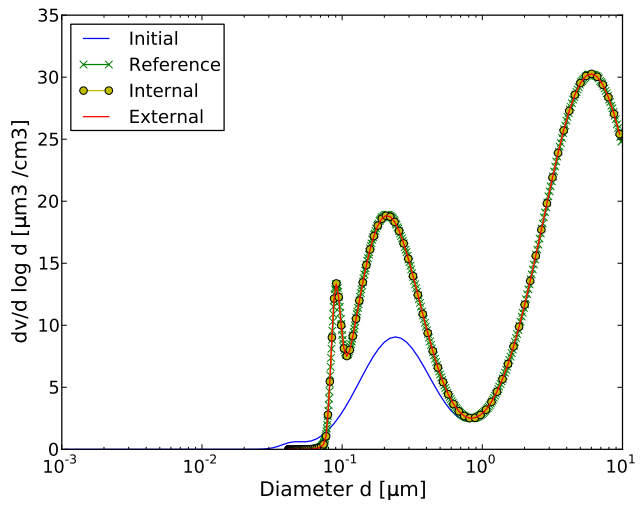

(b) Volume distribution

Figure 1. Simulation of condensation for hazy conditions: initial distribution and after $12 \mathrm{~h}$.

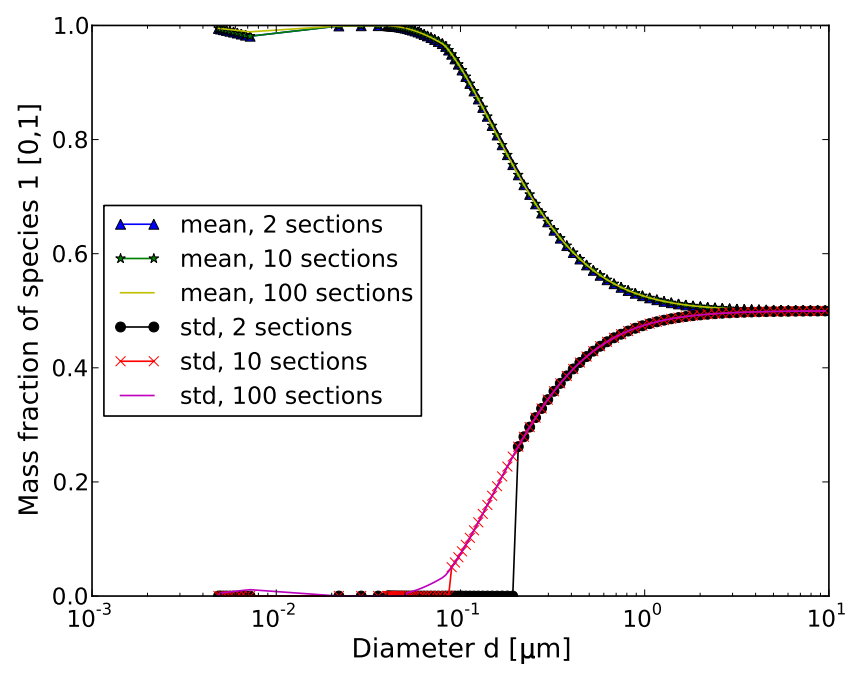

Figure 2. Mean and standard deviations of species 1 mass fraction as functions of particle diameter using 2, 10 and 100 composition sections.

on 1 July 2009. The highest emission rate is located at the grid cell centre of longitude and latitude $\left(2.28^{\circ} \mathrm{E}, 48.88^{\circ} \mathrm{N}\right)$, which was selected here to extract the SCRAM simulation input data for emissions, background gas and aerosol concentrations, and initial meteorological conditions (temperature and pressure). In the absence of specific information on individual particle composition, all initial aerosol concentrations extracted from the database were assumed to be $100 \%$ mixed (i.e. aged background aerosols).

Simulations start at 02:00 UT (1 July 2009), i.e. just before the morning peak of traffic emissions, and last $12 \mathrm{~h}$. As our simulations are $0 \mathrm{D}$, the transport of gases and particles and the deposition processes are not taken into account. Therefore, emissions accumulate, potentially leading to unrealistically high concentrations. To avoid this artifact, the duration of the emissions was limited to the first $40 \mathrm{~min}$ of sim- ulation. This time duration is calculated using the average $\mathrm{BC}$ emission rate between 02:00 and 03:00 UT, so that $\mathrm{BC}$ emissions lead to an increase in $\mathrm{BC}$ concentrations equal to the difference between $\mathrm{BC}$ concentrations after and before the morning traffic peak, i.e. between 06:00 and 02:00 UT (Fig. 6). Besides, gas-phase chemistry (such as SOA formation) is not included in SCRAM, and is expected to be solved separately using a gas-phase chemistry scheme. In the simulations of this work, SOA originate either from initial conditions or they are emitted as semi-volatile organic compounds during the simulation. They partition between the gas and the aerosol phases by condensation/evaporation.

The size distribution ranging from 0.001 to $10 \mu \mathrm{m}$ was discretised into seven sections with bounds at $0.001,0.005$, $0.01,0.0398,0.1585,0.6310,2.5119$ and $10 \mu \mathrm{m}$. As in Couvidat et al. (2013), 31 particulate species were included in our simulations. In order to reduce the computational cost of the externally mixed simulations, these species were grouped into five groups based on their chemical nature, which influences the formation of particles and their optical properties. Black carbon, organic species, inorganic species and dust are separated. Although sulfate could be separated from nitrate and ammonium for optical properties or for comparisons to observations of mixing state (Healy et al., 2012), and although chloride and sodium could be grouped together in a marine environment, all inorganic species are grouped together here for the sake of simplicity. However, because the hydrophylic properties of the particles strongly influence their formation and cloud condensation nuclei, hydrophylic and hydrophobic organic species are separated. In summary, the hydrophilic inorganic group (HLI) contains five inorganic species (sodium, sulfate, nitrate, ammonium and chloride); the hydrophilic organic group (HLO) contains 9 hydrophilic surrogate organic species (BiA2D, BiA1D, BiA0D, GLYOXAL, MGLY, BiMT, BiPER, BiDER and BiMGA); the hydrophobic organic group (HBO) contains 14 hydrophobic surrogate organic species (AnBlP, AnBmP, BiBlP, BiBmP, 


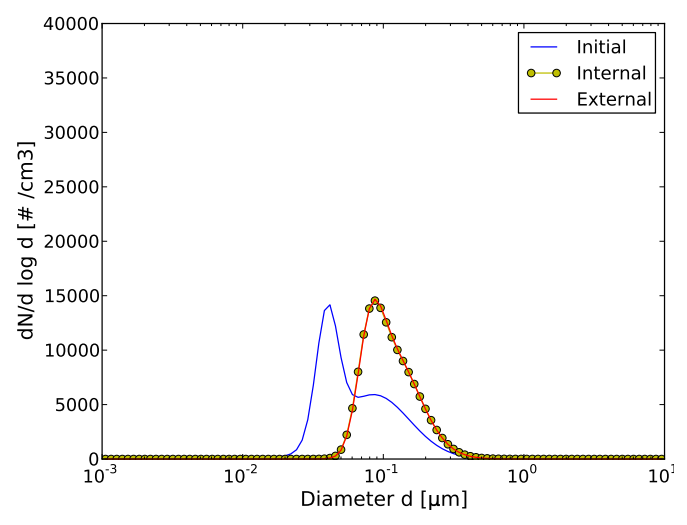

(a) Number distribution

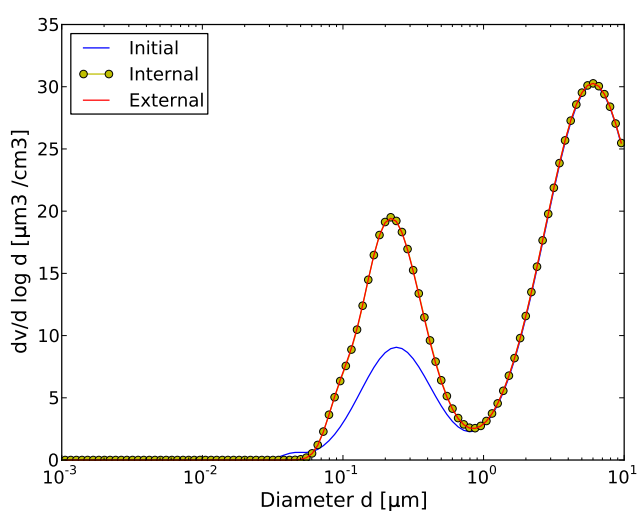

(b) Volume distribution

Figure 3. Simulation of both coagulation and condensation for hazy conditions: initial distribution and after $12 \mathrm{~h}$.

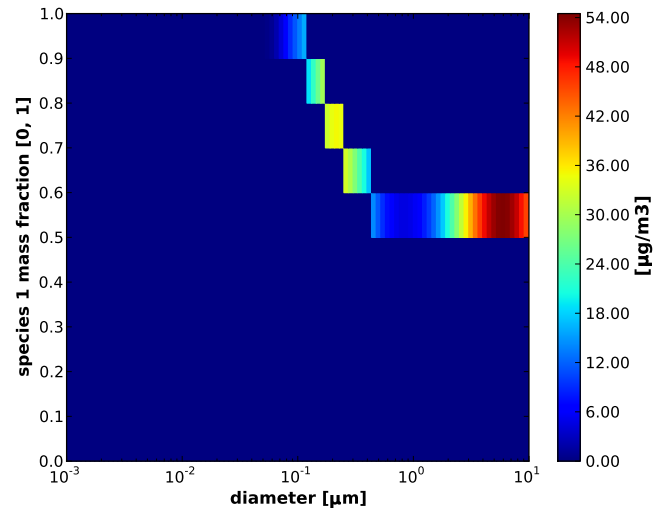

(a) Internal mixing

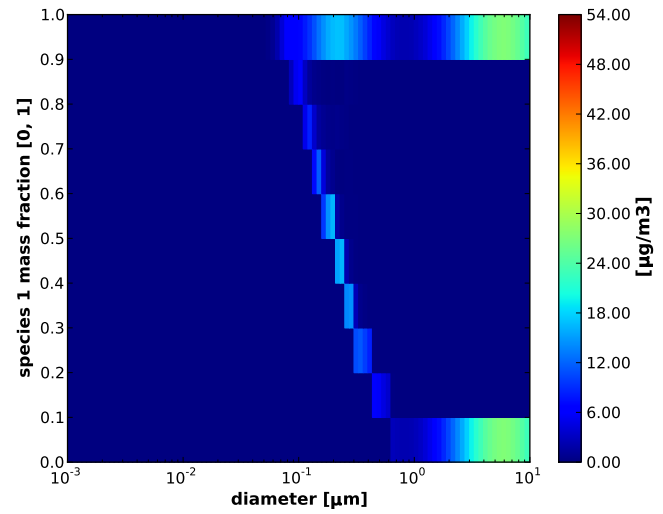

(b) External mixing

Figure 4. Distribution after $12 \mathrm{~h}$ : particle mass concentration as a function of diameter and mass fraction of species 1.

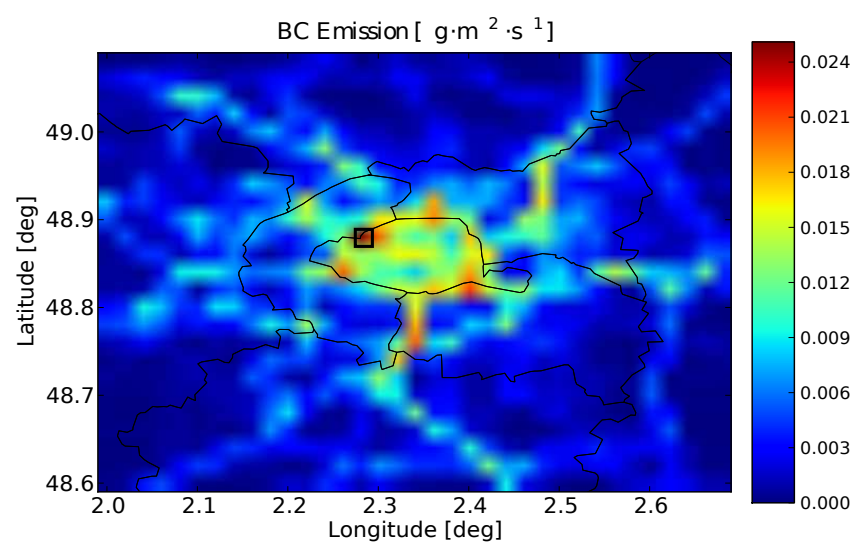

Figure 5. BC emissions over Greater Paris at 02:00 UT, 1 July 2009.

BiNGA, NIT3, BiNIT, AnCLP, SOAIP, SOAmP, SOAhP, POAlP, POAmP and POAhP); the black carbon group (BC) contains only black carbon; and the dust group (DU) contains all the neutral particles made up of soil, dust and fine sand.
Refer to Couvidat et al. (2012) for detailed nomenclature of the organic species. For each of the first four groups, the mass fraction of the group over the total mass is discretised into 3 mass fraction sections $([0.0,0.2),(0.2,0.8],(0.8,1.0])$, leading to 20 possible particle composition sections, as shown in Table 1. Among them, there are 5 unmixed particles and 15 mixed particles. Here "unmixed" is used in an approximate sense: it means that the mass fraction of one chemical component group is high (between 0.8 and 1), while the mass fractions of the other chemical component groups are low (between 0 and 0.2). The dust mass fraction is not discretised, as it is obtained by mass conservation. Note that although as an example we chose dust to be the group for which mass fraction is not treated explicitly, another group could be chosen as the group for which mass fraction is not treated explicitly. If all groups need to have their mass fraction treated explicitly, additional composition sections for the last group could be added to the current composition list without any modification to the main structure of the SCRAM code. The mass fraction of the last group would still be obtained by 


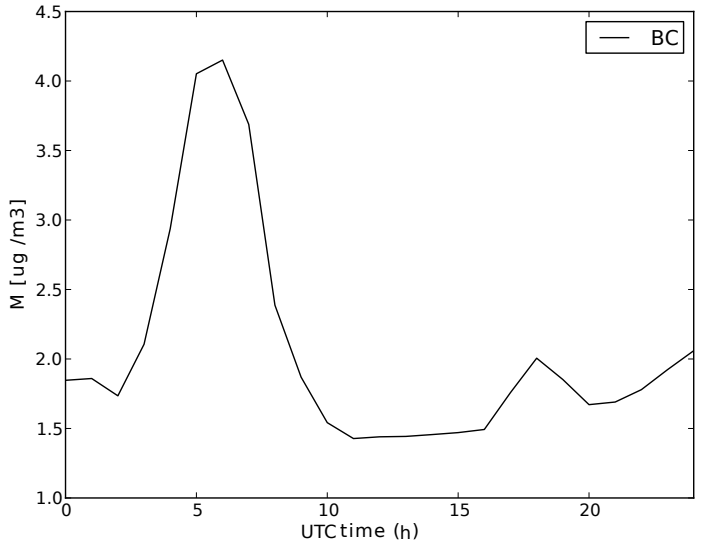

Figure 6. Transport BC concentration profile of 1 July 2009.

mass conservation, and the composition section of the particles would be chosen depending on this mass fraction.

In each group, water may also be present, although it is not considered when computing the mass fractions (it is calculated separately with the thermodynamic equilibrium models).

The model memorises the relationship between each species index and group index, and it stores the mass concentrations separately for each species within each sizecomposition section. The total mass concentration of each group is computed from the mass concentration of each species based on the species-group relations, allowing the computation of the mass fraction of each group.

\subsection{Aerosol dynamics and mixing state}

To understand how initial concentrations mix with emissions, four scenarios were simulated. In scenario (A), only emissions are taken into account in the simulation. Only coagulation is added to emissions in scenario (B), while only condensation/evaporation $(\mathrm{C} / \mathrm{E})$ is added to emissions in scenario (C). In scenario (D), emissions and all the aerosol dynamic processes are taken into account, including nucleation (however, no nucleation occurred during the simulation due to low sulfuric acid gas concentrations).

The mass and number distributions of each chemical composition after $12 \mathrm{~h}$ of simulation are shown in Figs. 7 and 8 as a function of particle diameter, as well as their initial distributions in sub-figure (e). Bars with greyscale represent unmixed particles, while bars with colours are mixed particles. Each bar corresponds to a chemical composition index (CI). However, any $\mathrm{CI}$ with a small number or mass concentrations are not really visible from the plot, so they are regrouped into mixed-other (for mixed CI) and unmixed-other (for unmixed $\mathrm{CI}$ ) in the plot. The chemical compositions and the CI value associated with colour bars are listed in Table 1. All emitted particles are unmixed: CI 1 (100\% DU) into size section (46), CI 3 (100\% BC) into size section (3-6). So any mixed
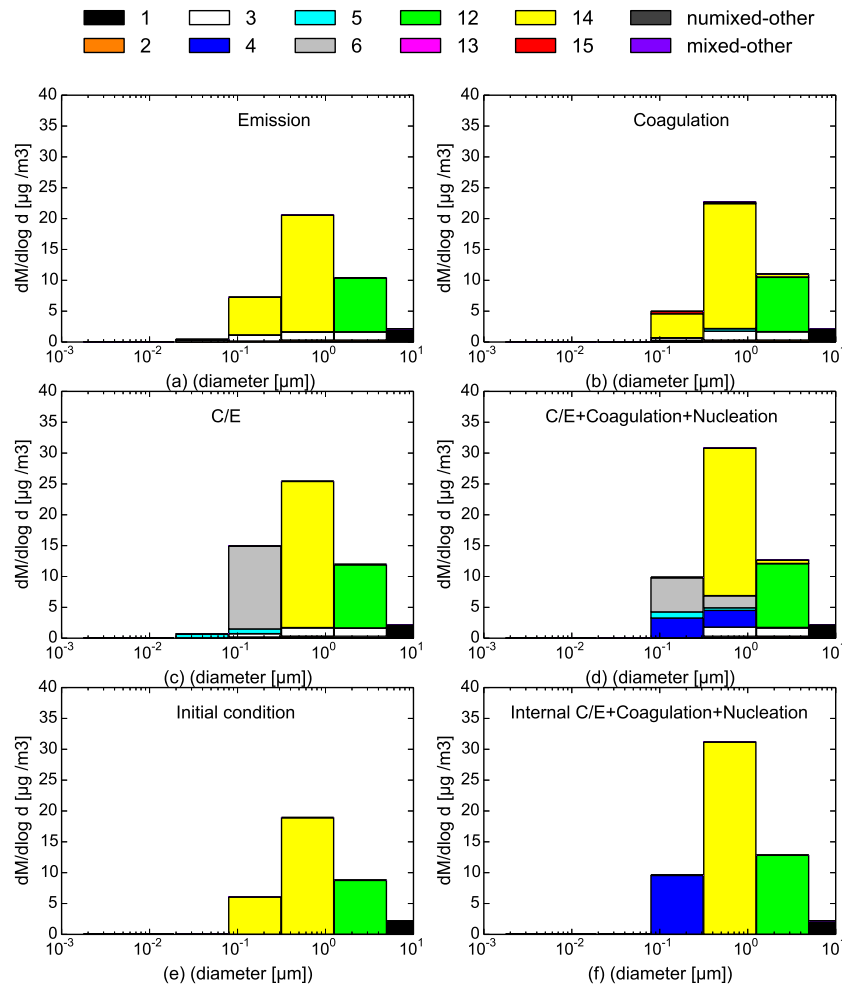

Figure 7. Result mass distributions of externally mixed particles as a function of particle diameter for the different chemical compositions for six different simulation scenarios: (a) emission only; (b) emission + coagulation; (c) emission+C/E; (d) emission + coagulation $+\mathrm{C} / \mathrm{E}+$ nucleation; (e) initial condition; and (f) internal mixing result.

particles represented in sub-figure (a) of Figs. 7 and 8 are due to initial condition instead of emissions. Besides, emissions also involve gas-phase $\mathrm{POA}$ and $\mathrm{H}_{2} \mathrm{SO}_{4}$, which can not be observed in sub-figure (a) of Figs. 7 and 8 as they has no interaction with particle phase under scenario (A). Organic vapours which may lead to the production of SOA are not included in the emissions, while a certain concentration of such vapours is defined within the initial condition.

As shown by the simulation of scenario (A), emissions lead to high number concentrations of BC in the sections of low diameters (mostly below $0.631 \mu \mathrm{m}$ ) and to high mass concentrations of dust and $\mathrm{BC}$ in the sections of high diameters (mostly above $0.631 \mu \mathrm{m}$ ).

The comparison of scenarios (A) and (B) shows that coagulation does not affect much mass concentrations, but significantly reduces the number concentrations of particles in the sections of diameters lower than $0.631 \mu \mathrm{m}$. Also, due to coagulation, small particles migrated to higher sections. For example, Fig. 8 shows the mixed CI 15 particles that originate from the third size section migrated to the fourth size section, and this could result from coagulation between CI 
Table 1. 20 externally mixed particle compositions.

\begin{tabular}{|c|c|c|c|c|c|c|}
\hline \multirow[t]{2}{*}{$\begin{array}{l}\text { Composition } \\
\text { index }\end{array}$} & \multirow[t]{2}{*}{$\begin{array}{l}\text { Mixing } \\
\text { state }\end{array}$} & \multicolumn{5}{|c|}{$\begin{array}{l}\text { Mass fraction of each groups } \\
(\%)\end{array}$} \\
\hline & & HLI & HLO & $\mathrm{HBO}$ & $\mathrm{BC}$ & DU \\
\hline 1 & Unmixed (DU) & $0-20$ & $0-20$ & $0-20$ & $0-20$ & $0-100$ \\
\hline 2 & Mixed & $0-20$ & $0-20$ & $0-20$ & $20-80$ & $0-80$ \\
\hline 3 & Unmixed (BC) & $0-20$ & $0-20$ & $0-20$ & $80-100$ & $0-20$ \\
\hline 4 & Mixed & $0-20$ & $0-20$ & $20-80$ & $0-20$ & $0-80$ \\
\hline 5 & Mixed & $0-20$ & $0-20$ & $20-80$ & $20-80$ & $0-60$ \\
\hline 6 & Unmixed HBO) & $0-20$ & $0-20$ & $80-100$ & $0-20$ & $0-20$ \\
\hline 7 & Mixed & $0-20$ & $20-80$ & $0-20$ & $0-20$ & $0-80$ \\
\hline 8 & Mixed & $0-20$ & $20-80$ & $0-20$ & $20-80$ & $0-60$ \\
\hline 9 & Mixed & $0-20$ & $20-80$ & $20-80$ & $0-20$ & $0-60$ \\
\hline 10 & Mixed & $0-20$ & $20-80$ & $20-80$ & $20-80$ & $0-40$ \\
\hline 11 & Unmixed (HLO) & $0-20$ & $80-100$ & $0-20$ & $0-20$ & $0-20$ \\
\hline 12 & Mixed & $20-80$ & $0-20$ & $0-20$ & $0-20$ & $0-80$ \\
\hline 13 & Mixed & $20-80$ & $0-20$ & $0-20$ & $20-80$ & $0-60$ \\
\hline 14 & Mixed & $20-80$ & $0-20$ & $20-80$ & $0-20$ & $0-60$ \\
\hline 15 & Mixed & $20-80$ & $0-20$ & $20-80$ & $20-80$ & $0-40$ \\
\hline 16 & Mixed & $20-80$ & $20-80$ & $0-20$ & $0-20$ & $0-60$ \\
\hline 17 & Mixed & $20-80$ & $20-80$ & $0-20$ & $20-80$ & $0-40$ \\
\hline 18 & Mixed & $20-80$ & $20-80$ & $20-80$ & $0-20$ & $0-40$ \\
\hline 19 & Mixed & $20-80$ & $20-80$ & $20-80$ & $20-80$ & $0-20$ \\
\hline 20 & Unmixed (HLI) & $80-100$ & $0-20$ & $0-20$ & $0-20$ & $0-20$ \\
\hline
\end{tabular}

Table 2. Mixing state after $12 \mathrm{~h}$ simulation.

\begin{tabular}{lllll}
\hline Process & $\begin{array}{l}\text { No Dynamic } \\
\text { scenario (A) }\end{array}$ & $\begin{array}{l}\text { Coagulation } \\
\text { scenario (B) }\end{array}$ & $\begin{array}{l}\text { C/E } \\
\text { scenario (C) }\end{array}$ & $\begin{array}{l}\text { C/E+Coag+Nucl } \\
\text { scenario (D) }\end{array}$ \\
\hline Mixed particle number (\%) & 42 & 79 & 48 & 51 \\
Mixed particle mass (\%) & 83 & 85 & 64 & 76 \\
\hline
\end{tabular}

14 size section 4 particles with CI 3 size section 3 particles, or between two CI 15 size section 3 particles.

As shown by the simulation of scenario (C), C/E leads to high mass and number concentrations of unmixed $\mathrm{HBO}$ (CI 6 - mass fraction of HBO (81.2\%) above $80 \%$ (exact mass fraction of the dominant group will be specified within the parentheses right after the group name here after)), increasing the amount of unmixed particles. Organic matter of low and medium volatilities is emitted in the gas phase following Couvidat et al. (2013). This organic matter condenses subsequently on well-mixed particles (CI 14 with mixed HLI $(31 \%)$ and HBO $(41 \%)$ ), in sufficient amount to increase the mass fraction of $\mathrm{HBO}(81 \%)$ to over $80 \%$ and, therefore, transfer particles to the unmixed category CI 6 (these particles are not exactly unmixed since up to $20 \%$ may correspond to HLI (10\%), but a finer composition resolution would be required to analyse their mixed characteristics). The condensation of organic matter on freshly emitted BC particles (CI 3) also occurs, as shown by the mixed BC
(26\%) and HBO (68\%) particles (CI 5) which appear in the third and fourth size sections.

As shown by comparing scenarios (A) and (B) and scenarios (C) and (D), coagulation significantly reduces number concentrations. The mass concentrations of fine particles (diameters lower than $0.631 \mu \mathrm{m}$ ) are also reduced. Furthermore, the composition diversity increases. For example, as demonstrated by the difference between scenarios (C) and (D), newly mixed particles of CI 4 (between 20 and $80 \%$ of HBO (78\% for size 4 and $73 \%$ for size 5)) are formed by the coagulation of unmixed particles from CI 6 with others within the fourth and fifth size sections.

Table 2 shows the percentage of mixed particles for each scenario based on both particle number and mass concentrations. It seems that large particles are better mixed than small particles as the mixing percentages of mass are always higher than those of number. However, this phenomenon is specific to this case study; it is caused by the assumption of all initial particles being internally mixed and the initial conditions 

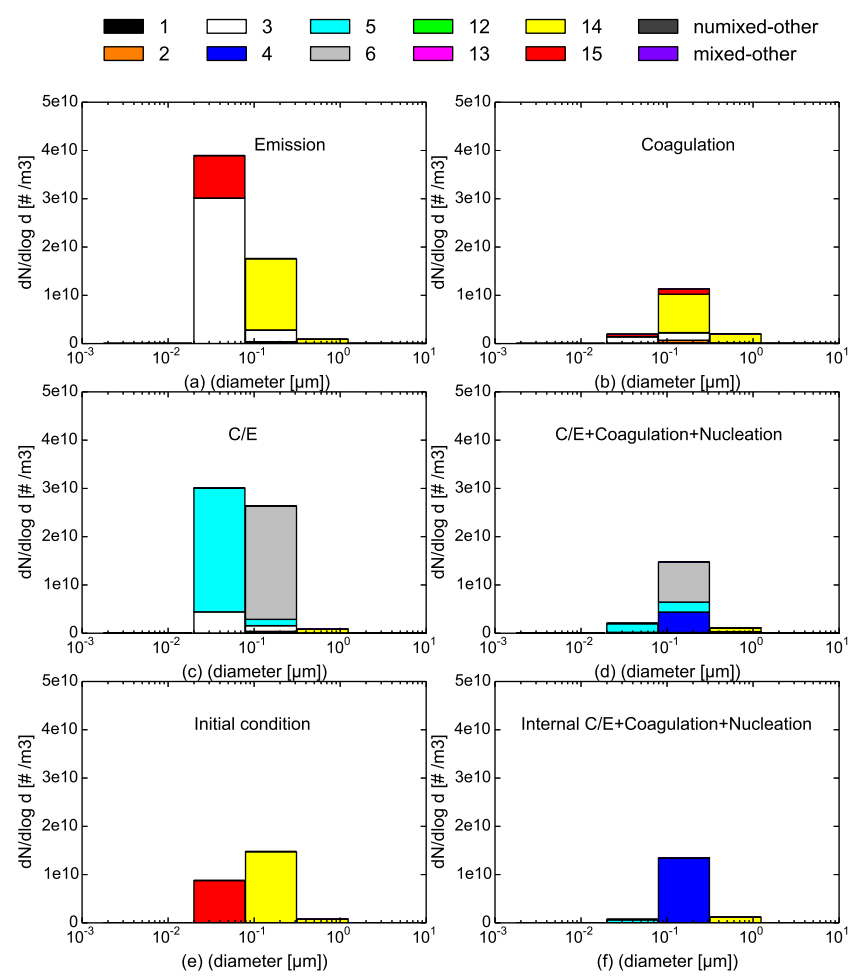

Figure 8. Result number distributions of externally mixed particles as a function of particle diameter for the different chemical compositions for six different simulation scenarios: (a) emission only; (b) emission + coagulation; (c) emission $+\mathrm{C} / \mathrm{E}$; (d) emission + coagulation $+\mathrm{C} / \mathrm{E}+$ nucleation; (e) initial condition; (f) internal mixing result.

dominating for large particles due to their low emissions and the short duration of the simulations.

The number/mass mixing percentages after emission only (scenario A) provide a baseline for the analysis of the three other scenarios. In scenario (A), $42 \%$ (resp. $83 \%$ ) of the particle number (resp. mass) originates from initial conditions and is mixed, while the remaining particles are due to emissions and are unmixed. The comparison of scenarios (A) and (B) shows that coagulation increases the mixing percentages, especially for small particles of high number concentrations. The mass mixing percentages decrease in scenario (C) because the condensation of freshly emitted organic matter on large mixed particles leads to particles with a mass fraction of organic matter (HBO) higher than $80 \%$, i.e. unmixed. When all aerosol dynamic processes are taken into account (scenario D), only $51 \%$ of particle number concentration and $76 \%$ of particle mass concentration are mixed. The mixing percentages are greater than those of scenario $(\mathrm{C})$, as mixing increases by coagulation, but the mass mixing percentage is lower than in scenario (A) (emissions only) because of the strong condensation of $\mathrm{HBO}$ emitted in the gas phase.
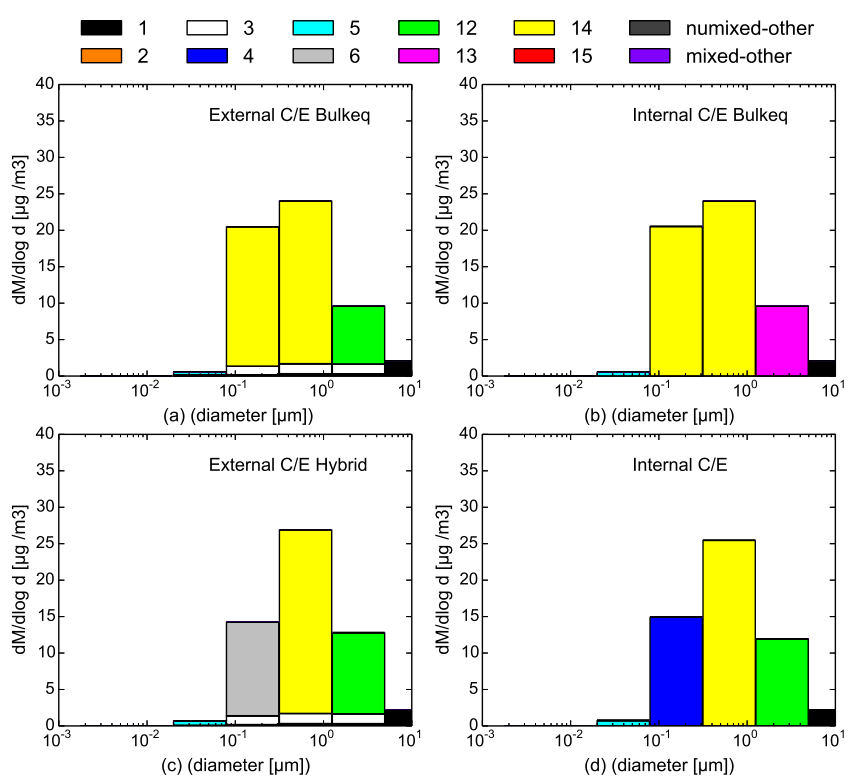

Figure 9. Result mass distributions of externally mixed particles as a function of particle diameter for the different chemical compositions for four different $\mathrm{C} / \mathrm{E}$ simulation scenarios: (a) external bulk equilibrium; (b) internal bulk equilibrium; (c) external hybrid method; and (d) internal dynamic.

\subsection{External versus internal mixing}

To investigate the consequence of the internal mixing hypothesis, a simulation of scenario (D) (all aerosol dynamic processes are taken into account) is conducted by assuming all particles to be internally mixed. Externally and internally mixed $12 \mathrm{~h}$ simulations lead to a similar total aerosol mass concentration after $12 \mathrm{~h}\left(33.09 \mu \mathrm{g} \mathrm{m}^{-3}\right.$ for internal mixing and $33.35 \mu \mathrm{g} \mathrm{m}^{-3}$ for external mixing) as well as to simi-

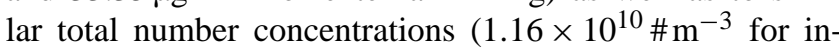
ternal mixing and $1.07 \times 10^{10} \mathrm{\# m}^{-3}$ for external mixing). The bulk mass concentrations of individual species are also similar, although external mixing leads to slightly lower ammonium concentrations $\left(2.68 \#^{-3}\right.$ versus $\left.2.70 \mathrm{\# m}^{-3}\right)$,

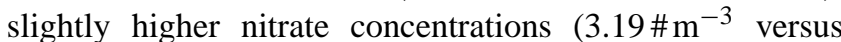

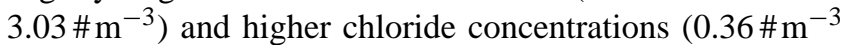
versus $0.25 \mathrm{\#} \mathrm{m}^{-3}$ ). The size distributions for number and for individual species masses are also very similar in the internal and external mixing simulations.

Figure $7 \mathrm{~d}$ and $\mathrm{f}$ compare the mass distributions and compositions within each size section after $12 \mathrm{~h}$ of the internal and external mixing simulations. External mixing provides more detail about the particle mixing state, as within each size section particles have different compositions. For example, in the case of internal mixing, particles in size section 4 (diameter between 0.0398 and $0.1585 \mu \mathrm{m}$ ) are all mostly hydrophobic organics (CI 4: HBO (76\%) between 20 and $80 \%)$. The particle compositions are more detailed in the external mixing simulation: while less than half of the particles 

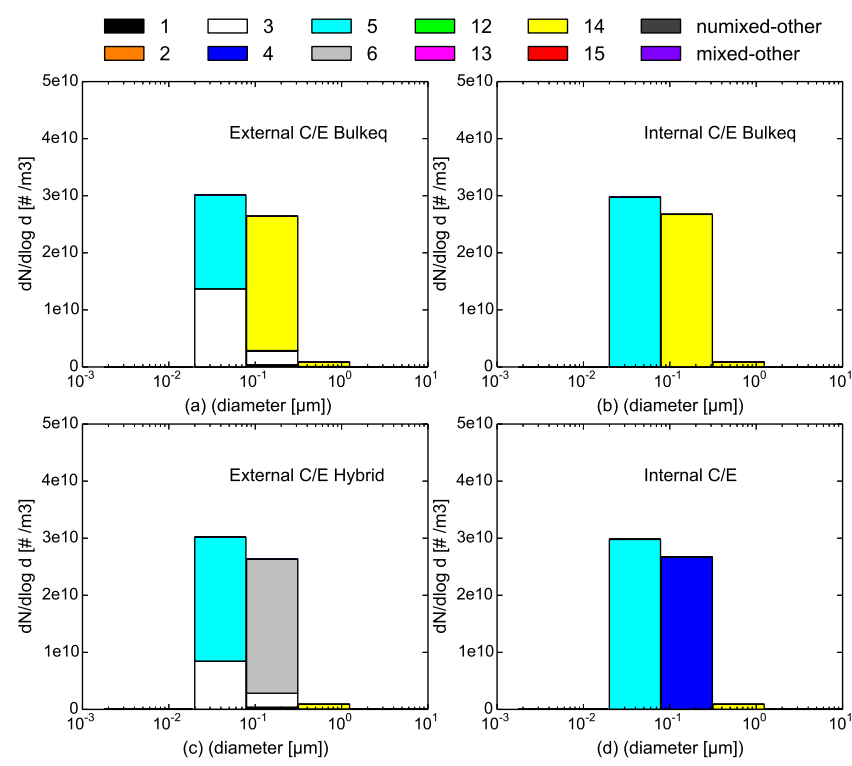

Figure 10. Result number distributions of externally mixed particles as a function of particle diameter for the different chemical compositions for four different $\mathrm{C} / \mathrm{E}$ simulation scenarios: (a) external bulk equilibrium; (b) internal bulk equilibrium; (c) external hybrid method; and (d) internal dynamic.

are mostly hydrophobic organics (HBO 78\%) (CI 4) as in internal mixing, a large amount are unmixed particles (CI 6: HBO (82\%) between 80 and $100 \%)$, and some are equally mixed with BC and hydrophobic organics (CI 5). In size section 5, as in the internal mixing simulation, mixed particles dominate (CI 14 - HLI 46\%, HBO 36\%), but many have a different composition (CI 4 and 5) and some are unmixed HBO $83 \%$ (CI 6), BC $91 \%$ (CI 3) and dust $90 \%$ (CI 1). For particles in size section 6 , particles are mixed particles of CI 12 (HLI $54 \%$,DU 29\%), while external mixing also shows that some particles are unmixed (BC $99 \%$ (CI 3) and dust $98 \%$ (CI 1)) and there are CI 14 (HLI 46\%, HBO $35 \%$ ) particles that originated from size section 5 through coagulation.

\subsection{Bulk equilibrium and hybrid approaches}

Additional external mixing tests were conducted using the bulk equilibrium and hybrid approaches for $\mathrm{C} / \mathrm{E}$ to evaluate both their accuracy and computational efficiency. In the hybrid approach, the lowest four sections are assumed to be at equilibrium (up to diameters of $0.1585 \mu \mathrm{m}$ ), whereas the other sections undergo dynamic mass transfer between the gas and particle phases.

The accuracy of these approaches is evaluated by comparing the mass and number distributions after $12 \mathrm{~h}$ simulations with the bulk equilibrium or the hybrid approaches to the mass and number distributions computed dynamically (see Figs. 9 and 10).

For externally mixed particles, the dynamic mass distribution is shown in Fig. 7c; the bulk equilibrium and hybrid mass distributions are shown in Fig. 9a and c, respectively. The dynamic number distribution is shown in Fig. 8c; the bulk equilibrium and hybrid mass distributions are shown in Fig. 10a and c, respectively. For internally mixed particles, the dynamic mass/number distributions are shown in Figs. 9d and $10 \mathrm{~d}$ and the bulk equilibrium mass/number distributions in Figs. 9b and 10b, respectively.

For internally mixed particles, the comparisons between Fig. $9 \mathrm{~b}$ and $d$ and between Fig. 10b and d indicate that the bulk equilibrium approach leads to significantly different distributions and compositions than the dynamic approach. This result also holds for externally mixed particles, as shown by the comparisons between Figs. 7c and 9a and between Figs. 8c and 10a. For example, more inorganic species condense on particles in the fourth size section (between 0.0398 and $0.1585 \mu \mathrm{m}$ ) in the case of bulk equilibrium compared to the fully dynamic case. This section is dominated by $\mathrm{CI}$ 14 (HLI $33 \%$, HBO 61\%) (equal mixture of inorganic and hydrophobic organics) for bulk equilibrium, instead of CI 6 (HBO $81 \%$ ) (unmixed hydrophobic organics) for dynamic. Internal and external distributions are similar with the dynamic approach, as well as with the bulk equilibrium approach. Although internal and external compositions are different with the dynamic approach, they are quite similar with the bulk equilibrium approach. However, with the bulk equilibrium approach, similarly to the dynamic approach, unmixed particles of CI 3 (unmixed BC) remain present in most size sections for externally mixed particles.

The mass and number distributions and compositions obtained with the hybrid approach are similar to the fully dynamic approach. For example, the over-condensation of inorganic species in the fourth size section (leading to particles of CI 14 (HLI $33 \%$, HBO 61 \%) with bulk equilibrium) is restrained with the hybrid approach, as the fourth size section is computed dynamically, and particles consist of CI 6 (HBO $81 \%$ ), as with the dynamic approach.

Table 3 shows the computational times (CPU) required for each simulation on a DELL Precision T3500 workstation (the lowest integration time step: 1). External mixing requires more $\mathrm{CPU}$, especially for computing coagulation and dynamic $\mathrm{C} / \mathrm{E}$. The largest difference between internal and external mixing occurs for computing coagulation, which is almost 800 times slower with external mixing. Bulk equilibrium $\mathrm{C} / \mathrm{E}$ provides a huge economy in $\mathrm{CPU}$ time for all simulations compared to dynamic $\mathrm{C} / \mathrm{E}$, while the computational advantage of hybrid $\mathrm{C} / \mathrm{E}$ is more obvious for internal mixing (17 times faster than dynamic $\mathrm{C} / \mathrm{E}$ ) than external mixing ( $15 \%$ faster than dynamic $\mathrm{C} / \mathrm{E})$. This significant speed degradation of the hybrid $\mathrm{C} / \mathrm{E}$ scheme in the external mixing case is probably a consequence of small time steps used in the ROS2 solver because of the redistribution among the different composition sections performed after each time step. In other words, it takes CPU time to compute the dynamic distribution among the different composition sections. 
Table 3. Computational times.

\begin{tabular}{llllllll}
\hline Process & $\mathrm{C} / \mathrm{E}$ & $\mathrm{C} / \mathrm{E}$ bulk & $\mathrm{C} / \mathrm{E}$ hybrid & Coag & $\mathrm{C} / \mathrm{E}+\mathrm{Coag}$ & $\mathrm{C} / \mathrm{E}+$ Coag bulk & $\mathrm{C} / \mathrm{E}+\mathrm{Coag}$ hybrid \\
\hline Internal mixing(s) & 7.1 & 0.11 & 0.4 & 0.06 & 7.3 & 0.14 & 0.5 \\
External mixing(s) & 63.2 & 0.3 & 54.2 & 48.4 & 122.8 & 31.5 & 113 \\
\hline
\end{tabular}

\section{Conclusions}

The new Size-Composition Resolved Aerosol Model (SCRAM) has been developed to simulate the dynamic evolution of externally mixed particles due to coagulation, condensation/evaporation, and nucleation. The general dynamic equation is discretised for both size and composition. Particle compositions are represented by the combinations of mass fractions, which may be chosen to correspond either to the mass fraction of the different species or to the mass fraction of groups of species (e.g. inorganic, hydrophobic organics, etc.). The total numbers and bounds of the size and composition sections are defined by the user. An automatic classification method is designed within the system to determine all the possible particle compositions based on the combinations of user-defined chemical species or groups and their mass-fraction sections.

The model was first validated by comparison to internally mixed simulations of condensation/evaporation of sulfuric acid and of condensation/evaporation of sulfuric acid with coagulation. It was also validated for condensation against a reference solution.

The model was applied using realistic concentrations and typical emissions of air pollution over Greater Paris, where traffic emissions are high. Initial concentrations were assumed to be internally mixed. Simulations lasted $12 \mathrm{~h}$.

Although internally and externally mixed simulations lead to similar particle size distributions, the particle compositions are different. The externally mixed simulations provide details about particle mixing states within each size section when compared to internally mixed simulations. After $12 \mathrm{~h}$, $49 \%$ of number concentrations and $24 \%$ of mass concentrations are not mixed. These percentages may be higher in 3-D simulations, because initial aerosol concentrations should not be assumed as entirely internally mixed over an urban area. Coagulation is quite efficient at mixing particles, as $52 \%$ of number concentrations and $36 \%$ of mass concentrations are not mixed if coagulation is not taken into account in the simulation. On the opposite end, condensation may decrease the percentage of mixed particles when low-volatility gaseous emissions are high.
Assuming bulk equilibrium when solving condensation/evaporation leads to different size and composition distributions than the dynamic approach under both the internally and externally mixed assumptions. With the bulk equilibrium approach, internally and externally mixed assumptions lead to similar average compositions as a function of size, and unmixed particles remain under the externally mixed assumption, which were also observed with the dynamic $\mathrm{C} / \mathrm{E}$ approach.

Although the simulation of externally mixed particles increases the computational cost, SCRAM offers the possibility to investigate particle mixing state in a comprehensive manner. Besides, its mixing state representation is flexible enough to be modified by users. Better computational performance could be reached with fewer, yet appropriately specified species groups and more optimised composition discretisations. For example, about half of the 20 compositions designed in this work have really low mass concentrations (e.g. see Figs. 7, 8, 9 and 10). Those compositions might be dynamically deactivated in the future version of SCRAM to lower computational cost by using an algorithm to skip empty sections during coagulation and $\mathrm{C} / \mathrm{E}$ processing.

Future work will focus on the optimisation and incorporation of SCRAM into the Polyphemus air quality modelling platform for 3-D simulations. In order to investigate its performance in modelling air quality over Greater Paris, model simulation results will be compared to observations (Healy et al., 2012). 


\section{Appendix A: Change of variables for the evolution of number and mass distributions}

This appendix describes how to derive the equations of change for the number concentration $\bar{n}$ and mass concentration $\bar{q}$ distributions as a function of the variables $f_{1}, \ldots, f_{(c-1)}, m$ used in the external mixing formulation.

To derive the equation of change for $\bar{n}\left(f_{1}, \ldots, f_{(c-1)}, m\right)$ (Eq. 5) from the equation of change for $n\left(m_{1}, \ldots, m_{c}\right)$ (Eq. 1), we need to perform a change of variables from $m_{1}, \ldots, m_{c}$ to $f_{1}, \ldots, f_{(c-1)}, m$ and to compute the $[c \times c]$ Jacobian Matrix $\mathbf{J}\left(f_{1}, f_{2}, \cdots, f_{(c-1)}, m\right)$

$$
\begin{aligned}
\mathbf{J} & =\left[\begin{array}{ccccc}
\frac{\partial m_{1}}{\partial f_{1}} & \frac{\partial m_{1}}{\partial f_{2}} & \cdots & \frac{\partial m_{1}}{\partial f_{(c-1)}} & \frac{\partial m_{1}}{\partial m} \\
\frac{\partial m_{2}}{\partial f_{1}} & \frac{\partial m_{2}}{\partial f_{2}} & \cdots & \frac{\partial m_{2}}{\partial f_{(c-1)}} & \frac{\partial m_{2}}{\partial m} \\
\vdots & \vdots & \ddots & \vdots & \vdots \\
\frac{\partial m_{(c-1)}}{\partial f_{1}} & \frac{\partial m_{(c-1)}}{\partial f_{2}} & \cdots & \frac{\partial m_{(c-1)}}{\partial f_{(c-1)}} & \frac{\partial m_{(c-1)}}{\partial m_{1}} \\
\frac{\partial m_{c}}{\partial f_{1}} & \frac{\partial m_{c}}{\partial f_{2}} & \cdots & \frac{\partial m_{c}}{\partial f_{(c-1)}} & \frac{\partial m_{c}}{\partial m}
\end{array}\right] \\
& =\left[\begin{array}{ccccc}
m & 0 & \cdots & 0 & f_{1} \\
0 & m & \cdots & 0 & f_{2} \\
\vdots & \vdots & \ddots & \vdots & \vdots \\
0 & 0 & \cdots & m & f_{(c-1)} \\
-m & -m & \cdots & -m & 1-\sum_{i=1}^{(c-1)} f_{i}
\end{array}\right]
\end{aligned}
$$

and the Jacobian inverse matrix:

$\mathbf{J}^{-1}=\left[\begin{array}{ccccc}\frac{1-f_{1}}{m_{f_{2}}} & -\frac{f_{1}}{m} & \cdots & -\frac{f_{1}}{m} & -\frac{f_{1}}{m} \\ -\frac{f_{2}}{m} & \frac{1-f_{2}}{m} & \cdots & -\frac{f_{2}}{m} & -\frac{f_{2}}{m} \\ \vdots & \vdots & \ddots & \vdots & \vdots \\ -\frac{f_{(c-1)}}{m} & -\frac{f_{(c-1)}}{m} & \cdots & \frac{1-f_{(c-1)}}{m} & -\frac{f_{(c-1)}}{m} \\ 1 & 1 & \cdots & 1 & 1 .\end{array}\right]$

The relationship between $n$ and $\bar{n}$ is

$n=\frac{\bar{n}}{\operatorname{det}(J)}=\frac{\bar{n}}{m^{(c-1)}}$.

Thus,

$\frac{\partial n}{\partial t}=\frac{\partial\left(\frac{\bar{n}}{m^{(c-1)}}\right)}{\partial t}=\frac{1}{m^{(c-1)}} \frac{\partial \bar{n}}{\partial t}$.

For the right-hand side of Eq. (1), the terms $\frac{\partial\left(I_{i} n\right)}{\partial m_{i}}$ are replaced by terms depending on the new variables, using

$$
\begin{aligned}
& \left(\frac{\partial\left(I_{1} n\right)}{\partial m_{1}}, \frac{\partial\left(I_{2} n\right)}{\partial m_{2}}, \cdots, \frac{\partial\left(I_{c} n\right)}{\partial m_{c}}\right)= \\
& \left(\frac{\partial\left(I_{1} n\right)}{\partial f_{1}}, \frac{\partial\left(I_{2} n\right)}{\partial f_{2}}, \cdots, \frac{\partial\left(I_{(c-1)} n\right)}{\partial f_{(c-1)}}, \frac{\partial\left(I_{c} n\right)}{\partial m}\right) \times \mathbf{J}^{-1} .
\end{aligned}
$$

For $i \in(1,(c-1))$, this leads to:

$$
\frac{\partial\left(I_{i} n\right)}{\partial m_{i}}=\frac{1}{m} \frac{\partial\left(I_{i} n\right)}{\partial f_{i}}-\sum_{j=1}^{(c-1)} \frac{f_{j}}{m} \frac{\partial\left(I_{i} n\right)}{\partial f_{j}}+\frac{\partial\left(I_{i} n\right)}{\partial m}
$$

and for $i=c$ :

$\frac{\partial\left(I_{c} n\right)}{\partial m_{c}}=-\sum_{j=1}^{(c-1)} \frac{f_{j}}{m} \frac{\partial\left(I_{c} n\right)}{\partial f_{j}}+\frac{\partial\left(I_{c} n\right)}{\partial m}$.

If we replace $I_{c}$ with $I_{0}-\sum_{i=1}^{(c-1)} I_{i}$ in (A7), we have

$$
\begin{aligned}
& \frac{\partial\left(I_{c} n\right)}{\partial m_{c}}=-\sum_{j=1}^{(c-1)} \frac{f_{j}}{m} \frac{\partial\left(I_{0} n\right)}{\partial f_{j}}+\sum_{i=1}^{(c-1)} \sum_{j=1}^{(c-1)} \frac{f_{j}}{m} \frac{\partial\left(I_{i} n\right)}{\partial f_{j}} \\
& +\frac{\partial\left(I_{0} n\right)}{\partial m}-\sum_{i=1}^{(c-1)} \frac{\partial\left(I_{i} n\right)}{\partial m} .
\end{aligned}
$$

The sum of the first $(c-1)$ terms of the right side of Eq. (1) may be written as follows.

$$
\begin{aligned}
\sum_{i=1}^{(c-1)} \frac{\partial\left(I_{i} n\right)}{\partial m_{i}}= & \frac{1}{m} \sum_{i=1}^{(c-1)} \frac{\partial\left(I_{i} n\right)}{\partial f_{i}}-\sum_{i=1}^{(c-1)} \sum_{j=1}^{(c-1)} \frac{f_{j}}{m} \frac{\partial\left(I_{i} n\right)}{\partial f_{j}} \\
& +\sum_{i=1}^{(c-1)} \frac{\partial\left(I_{i} n\right)}{\partial m} .
\end{aligned}
$$

The right-hand side of Eq. (1) becomes

$-\sum_{i=1}^{c} \frac{\partial\left(I_{i} n\right)}{\partial m_{i}}=-\sum_{i=1}^{(c-1)} \frac{\partial\left(I_{i} n\right)}{\partial m_{i}}-\frac{\partial\left(I_{c} n\right)}{\partial m_{c}}=$

$-\frac{1}{m} \sum_{i=1}^{(c-1)} \frac{\partial\left(I_{i} n\right)}{\partial f_{i}}+\sum_{i=1}^{(c-1)} \frac{f_{i}}{m} \frac{\partial\left(I_{0} n\right)}{\partial f_{i}}-\frac{\partial\left(I_{0} n\right)}{\partial m}$.

If we denote $H_{i}=\frac{\partial f_{i}}{\partial t}$, then $I_{i}$ may be written as follows.

$I_{i}=\frac{\partial m_{i}}{\partial t}=\frac{\partial\left(m f_{i}\right)}{\partial t}=m \frac{\partial f_{i}}{\partial t}+f_{i} \frac{\partial m}{\partial t}=m H_{i}+f_{i} I_{0}$.

Replacing $I_{i}$ by Eq. (A11) in Eq. (A10) and using $\frac{\partial m}{\partial f_{i}}=0$,

$$
\begin{aligned}
-\sum_{i=1}^{c} \frac{\partial\left(I_{i} n\right)}{\partial m_{i}}= & -\frac{1}{m} \sum_{i=1}^{(c-1)} \frac{\partial\left(m H_{i} n+f_{i} I_{0} n\right)}{\partial f_{i}} \\
& +\sum_{i=1}^{(c-1)} \frac{f_{i}}{m} \frac{\partial\left(I_{0} n\right)}{\partial f_{i}}-\frac{\partial\left(I_{0} n\right)}{\partial m} \\
= & -\sum_{i=1}^{(c-1)} \frac{\partial\left(H_{i} n\right)}{\partial f_{i}}-\frac{(c-1)}{m} I_{0} n \\
& -\frac{\partial\left(I_{0} n\right)}{\partial m} .
\end{aligned}
$$

Replacing $n$ with $\frac{\bar{n}}{m^{(c-1)}}$ in Eq. (1) and using Eq. (A12), we have

$$
\begin{aligned}
\frac{1}{m^{(c-1)}} \frac{\partial \bar{n}}{\partial t} & =-\sum_{i=1}^{(c-1)} \frac{\partial\left(H_{i} \frac{\bar{n}}{m^{(c-1)}}\right)}{\partial f_{i}}-\frac{(c-1)}{m^{c}} I_{0} \bar{n}-\frac{\partial\left(I_{0} \frac{\bar{n}}{m^{(c-1)}}\right)}{\partial m} \\
& =-\frac{1}{m^{(c-1)}} \sum_{i=1}^{(c-1)} \frac{\partial\left(H_{i} \bar{n}\right)}{\partial f_{i}}-\frac{1}{m^{(c-1)}} \frac{\partial\left(I_{0} \bar{n}\right)}{\partial m}
\end{aligned}
$$


(A13)

and the equation of change for $\bar{n}$ is finally

$$
\frac{\partial \bar{n}}{\partial t}=-\sum_{i=1}^{(c-1)} \frac{\partial\left(H_{i} \bar{n}\right)}{\partial f_{i}}-\frac{\partial\left(I_{0} \bar{n}\right)}{\partial m}
$$

The equation of change for the mass distribution $q_{i}=n m_{i}$ of species $i$ is derived as follows.

$\frac{\partial q_{i}}{\partial t}=\frac{\partial n m_{i}}{\partial t}=-m_{i} \frac{\partial n}{\partial t}+n I_{i}$.

And the equation of change for $\bar{q}_{i}$ is obtained using $n=$ $\frac{\bar{n}}{m^{(c-1)}}, q_{i}=\frac{\bar{q}_{i}}{m^{(c-1)}}$ and $m_{i}=m f_{i}$ :

$\frac{\partial \bar{q}_{i}}{\partial t}=-m f_{i} \frac{\partial \bar{n}}{\partial t}+\bar{n} I_{i}$

\section{Appendix B: The time derivation of Eq. (10) and (9)}

The time derivation of Eq. (10) leads to

$$
\frac{\partial N^{j}}{\partial t}=\overbrace{\int_{m_{k}^{-}}^{m_{k}^{+} f_{g_{g_{1}}^{+}}^{+}} \ldots \int_{f_{g_{(c-1)}^{-}}^{-}}^{f_{g_{(c-1)}}^{+}} \frac{\partial \bar{n}}{\partial t} \mathrm{~d} m \mathrm{~d} f_{g_{1}}, \ldots, \mathrm{d} f_{g_{(c-1)}}}^{A}
$$$$
+\overbrace{\frac{\mathrm{d} m_{k}^{+}}{\mathrm{d} t} \int_{f_{g_{1}}^{-}}^{f_{g_{1}}^{+}} \ldots \int_{f_{g_{(c-1)}^{-}}^{-}}^{f_{g_{(c-1)}}^{+}} \bar{n}\left(m_{k}^{+}, f_{g_{1}}, \ldots, f_{g_{(c-1)}}\right) \mathrm{d} f_{g_{1}}, \ldots, \mathrm{d} f_{g_{(c-1)}}}^{B}
$$$$
-\frac{\mathrm{d} m_{k}^{-}}{\mathrm{d} t} \int_{f_{g_{1}}^{-}}^{f_{g_{1}}^{+}} \ldots \int_{f_{g_{(c-1)}}^{-}}^{f_{g_{(c-1)}}^{+}} \bar{n}\left(m_{k}^{-}, f_{g_{1}}, \ldots, f_{g_{(c-1)}}\right) \mathrm{d} f_{g_{1}}, \ldots, \mathrm{d} f_{g_{(c-1)}}
$$$$
+\sum_{i=1}^{(c-1)}\left[\frac{\mathrm{d} f_{g_{i}}^{+}}{\mathrm{d} t} \int_{m_{k}^{-}}^{m_{k}^{+}} \int_{f_{g_{1}}^{-}}^{f_{g_{1}}^{+}} \ldots \int_{f_{g_{i-1}}^{-}}^{f_{g_{i-1}}^{+}} \int_{f_{g_{i+1}}^{-}}^{f_{g_{i+1}}^{+}} \cdots \int_{f_{g_{(c-1)}^{-}}^{-}}^{f_{g_{(c-1)}}^{+}}\right.
$$

$\bar{n}\left(m, f_{g_{1}}, \ldots, f_{g_{i-1}}, f_{g_{i}^{+}}, f_{g_{i+1}}, \ldots, f_{g_{(c-1)}}\right)$

$\mathrm{d} m \mathrm{~d} f_{g_{1}} \ldots \mathrm{d} f_{g_{i-1}} \mathrm{~d} f_{g_{i+1}} \ldots \mathrm{d} f_{g_{(c-1)}}$

$$
-\frac{\mathrm{d} f_{g_{i}}^{-}}{\mathrm{d} t} \int_{m_{k}^{-}}^{m_{k}^{+}} \int_{f_{g_{1}}^{-}}^{f_{g_{1}}^{+}} \ldots \int_{f_{g_{i-1}}^{-}}^{f_{g_{i-1}}^{+}} \int_{f_{g_{i+1}}^{-}}^{f_{g_{i+1}}^{+}} \ldots \int_{f_{g_{(c-1)}}^{-}}^{f_{g_{(c-1)}}^{+}}
$$

$\bar{n}\left(m, f_{g_{1}}, \ldots, f_{g_{i-1}}, f_{g_{i}^{-}}, f_{g_{i+1}}, \ldots, f_{g_{(c-1)}}\right)$

$\left.\mathrm{d} m \mathrm{~d} f_{g_{1}} \ldots \mathrm{d} f_{g_{i-1}} \mathrm{~d} f_{g_{i+1}} \ldots \mathrm{d} f_{g_{(c-1)}}.\right]$
Replacing $\frac{\partial \bar{n}}{\partial t}\left(m, f_{g_{1}}, \ldots, f_{g_{(c-1)}}\right)$ by Eq. (5), we have

$$
\begin{gathered}
A=\int_{m_{k}^{-}}^{m_{f_{1}^{-}}^{-}} \ldots \int_{f_{g_{(c-1)}}^{+}}^{m_{g_{1}}^{+}}\left[-\frac{\partial\left(I_{0} n\right)}{\partial m}-\sum_{x=1}^{(c-1)} \frac{\partial\left(H_{g_{x}} n\right)}{\partial f_{g_{x}}}\right] \\
\mathrm{d} m \mathrm{~d} f_{g_{1}} \ldots \mathrm{d} f_{g_{(c-1)}}^{+}
\end{gathered}
$$

and using $I_{0}=\frac{\mathrm{d} m}{\mathrm{~d} t}, H_{g_{i}}=\frac{\mathrm{d} f_{g_{i}}}{\mathrm{~d} t}$ and $\frac{\partial f_{g_{i}}}{\partial f_{g_{l}}}=0$ when $i \neq l$

$A=-\left\{\frac{\mathrm{d} m_{k}^{+}}{\mathrm{d} t} \int_{f_{g_{1}}^{-}}^{f_{g_{1}}^{+}} \ldots \int_{f_{g_{(c-1)}^{-}}^{-}}^{f_{g_{(c-1)}}^{+}} \bar{n}\left(m_{k}^{+}, f_{g_{1}}, \ldots, f_{g_{(c-1)}}\right)\right.$

$\mathrm{d} m \mathrm{~d} f_{g_{1}} \ldots \mathrm{d} f_{g_{(c-1)}}-\frac{\mathrm{d} m_{k}^{-}}{\mathrm{d} t} \int_{f_{g_{1}}^{-}}^{f_{g_{1}}^{+}} \ldots \int_{f_{g_{(c-1)}}^{-}}^{f_{g_{(c-1)}}^{+}} \bar{n}\left(m_{k}^{-}, f_{g_{1}}, \ldots, f_{g_{(c-1)}}\right)$

$\mathrm{d} m \mathrm{~d} f_{g_{1}} \ldots \mathrm{d} f_{g_{(c-1)}}$

$$
+\sum_{i=1}^{(c-1)}\left[\frac{\mathrm{d} f_{g_{i}}^{+}}{\mathrm{d} t} \int_{m_{k}^{-}}^{m_{k}^{+} f_{g_{1}}^{-}} \ldots \int_{f_{g_{i-1}}^{+}}^{f_{g_{1}}^{-}} \int_{f_{g_{+1}}^{-}}^{f_{g_{i-1}}^{+} f_{g_{i+1}}^{+}} \ldots \int_{f_{g_{(c-1)}^{-}}^{-}}^{f_{g_{(c-1)}}^{+}}\right.
$$

$\bar{n}\left(m, f_{g_{1}}, \ldots, f_{g_{i-1}}, f_{g_{i}^{+}}, f_{g_{i+1}}, \ldots, f_{g_{(c-1)}}\right)$

$\mathrm{d} m \mathrm{~d} f_{g_{1}} \ldots \mathrm{d} f_{g_{i-1}} \mathrm{~d} f_{g_{i+1}} \ldots \mathrm{d} f_{g_{(c-1)}}$

$$
-\frac{\mathrm{d} f_{g_{i}}^{-}}{\mathrm{d} t} \int_{m_{k}^{-}}^{m_{k}^{+}} \int_{f_{g_{1}}^{-}}^{m_{g_{1}}^{+}} \ldots \int_{f_{g_{i-1}}^{-}}^{f_{g_{i-1}}^{+}} \int_{f_{g_{i+1}}^{-}}^{f_{g_{i+1}}^{+}} \cdots \int_{f_{g_{(c-1)}}^{-}}^{f_{g_{(c-1)}}^{+}}
$$

$\bar{n}\left(m, f_{g_{1}}, \ldots, f_{g_{i-1}}, f_{g_{i}^{-}}, f_{g_{i+1}}, \ldots, f_{g_{(c-1)}}\right)$

$\left.\left.\mathrm{d} m \mathrm{~d} f_{g_{1}} \ldots \mathrm{d} f_{g_{i-1}} \mathrm{~d} f_{g_{i+1}} \ldots \mathrm{d} f_{g_{(c-1)}}\right]\right\}$

So $A=-B$; thus

$\frac{\partial N^{j}}{\partial t}=(A+B)=0$,

which is expected since condensation/evaporation does not affect the total number of particles.

Similarly, an equation of change can be derived for $Q_{i}^{j}$. In order to simplify the writing of the equations, the following abbreviations are introduced: 
$f_{g_{1}^{(c-1)}}=f_{g_{1}}, \ldots, f_{g_{(c-1)}}$

$f_{g_{1}^{(c-1)} \backslash i}=f_{g_{1}}, \ldots, f_{g_{i-1}}, f_{g_{i+1}}, \ldots, f_{g_{(c-1)}}$

$\mathrm{d} f_{g_{1}^{(c-1)}}=\mathrm{d} f_{g_{1}} \ldots \mathrm{d} f_{g_{(c-1)}}$

$\mathrm{d} f_{g_{1}^{(c-1)} \backslash i}=\mathrm{d} f_{g_{1}} \ldots \mathrm{d} f_{g_{i-1}} \mathrm{~d} f_{g_{i+1}} \ldots \mathrm{d} f_{g_{(c-1)}}$

$f_{g_{1}^{(c-1)}}^{+} \quad f_{g_{1}}^{+} \quad f_{g_{(c-1)}^{+}}^{+}$

$\int_{f_{g_{1}^{-}}^{-}(c-1)}^{\delta_{1}}=\int_{f_{g_{1}}^{-}} \cdots \int_{f_{g_{(c-1)}^{-}}^{-}}^{f_{(c)}^{+}}$

$f_{g_{1}^{(c-1)} \backslash i}^{+} \quad f_{g_{1}}^{+} \quad f_{g_{i-1}}^{+} f_{g_{i+1}}^{+} \quad f_{g_{(c-1)}}^{+}$

$\int=\int^{g_{1}} \ldots \int^{g_{1}} \ldots \int^{g_{i-1}}$.

$f_{g_{1}^{(c-1)} \backslash i}^{-} \quad f_{g_{1}}^{-} \quad f_{g_{i-1}}^{-} f_{g_{i+1}}^{-} \quad f_{g_{(c-1)}}^{-}$

The time derivation of Eq. (9) leads to

$$
\begin{aligned}
& \frac{\partial Q_{i}^{j}}{\partial t}=\int_{m_{k}^{-} f_{g_{1}^{-}(c-1)}^{m_{k}^{+}}}^{f_{g_{1}}^{+(c-1)}} \frac{\partial \overline{q_{i}}}{\partial t} \mathrm{~d} m \mathrm{~d} f_{g_{1}^{(c-1)}} \\
& +\frac{\mathrm{d} m_{k}^{+}}{\mathrm{d} t} \int_{f_{g_{1}}^{+}}^{f_{g_{1}^{(c-1)}}^{+}} \bar{q}_{i}\left(m_{k}^{+}, f_{g_{1}(c-1)}\right) \mathrm{d} f_{g_{1}^{(c-1)}}-\frac{\mathrm{d} m_{k}^{-}}{\mathrm{d} t} \int_{f_{g_{1}^{-}}^{-}}^{f_{g_{1}^{(c-1)}}^{+}} \\
& \bar{q}_{i}\left(m_{k}^{-}, f_{g_{1}^{(c-1)}}\right) \mathrm{d} f_{g_{1}^{(c-1)}} \\
& +\sum_{i=1}^{(c-1)}\left[\frac{\mathrm{d} f_{g_{1}^{(c-1)}}^{+}}{\mathrm{d} t} \int_{m_{k}^{-} f_{g_{1}^{-}}^{-(c-1)} \backslash i}^{m_{k}^{+} f_{g_{1}^{(c-1)} \backslash i}^{+}} \bar{q}_{i}\left(m, f_{g_{i}}^{+}, f_{g_{1}^{(c-1)} \backslash i}\right) \mathrm{d} m \mathrm{~d} f_{g_{1}^{(c-1)} \backslash i}\right.
\end{aligned}
$$

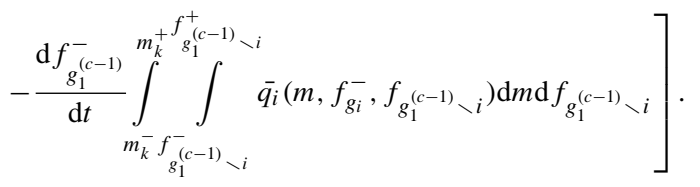

Substituting Eq. (A16) and $\bar{q}_{i}=m f_{i} \bar{n}$ into Eq. (B5), we obtain

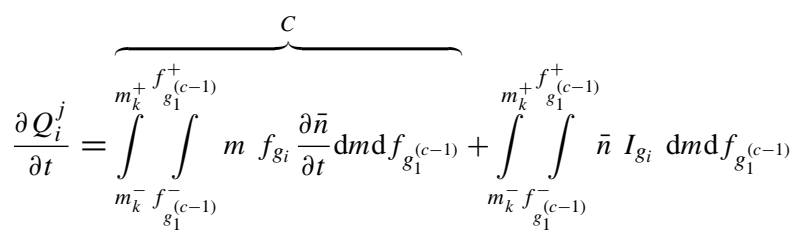

$$
\begin{aligned}
& \overbrace{f_{g_{1}^{(c-1)}}^{+}}^{D} \\
& +m_{k}^{+} \frac{\mathrm{d} m_{k}^{+}}{\mathrm{d} t} \int_{f_{g_{1}^{-(c-1)}}^{f_{g_{1}}^{(c-1)}}}^{f_{g_{i}}} \bar{n}\left(m_{k}^{+}, f_{g_{1}^{(c-1)}}\right) \mathrm{d} f_{g_{1}^{(c-1)}} \\
& -m_{k}^{-} \frac{\mathrm{d} m_{k}^{-}}{\mathrm{d} t} \int_{f_{g_{1}^{(c-1)}}^{-}}^{f_{g_{1}^{(c-1)}}^{+}} f_{g_{i}} \bar{n}\left(m_{k}^{-}, f_{g_{1}(c-1)}\right) \mathrm{d} f_{g_{1}^{(c-1)}}
\end{aligned}
$$

$$
+\sum_{i=1}^{(c-1)}\left[f_{g_{i}}^{+} \frac{\mathrm{d} f_{g_{1}^{(c-1)}}^{+}}{\mathrm{d} t} \int_{m_{k}^{-} f_{g_{1}^{-}(c-1)}^{m_{k}^{+}} \int_{g_{1}^{(c-1)}}^{f^{+} \backslash i}}^{m^{-}} m \bar{n}\left(m, f_{g_{i}}^{+}, f_{g_{1}^{(c-1)} \backslash i}\right)\right.
$$$$
\mathrm{d} m \mathrm{~d} f_{g_{1}^{(c-1)} \backslash i}
$$

$$
\left.-f_{g_{i}}^{-} \frac{\mathrm{d} f_{g_{1}}^{-}}{\mathrm{d} t} \int_{m_{k}^{-}(c-1)}^{m_{k}^{+}} \int_{g_{1}^{-(c-1)} \backslash i}^{f_{g_{1}}^{+(c-1)} \backslash i} m \bar{n}\left(m, f_{g_{i}}^{-}, f_{g_{1}^{(c-1)} \backslash i}\right) \mathrm{d} m \mathrm{~d} f_{g_{1}^{(c-1)} \backslash i}\right] .
$$

Similarly to Eq. (B1), it can be proved that $C=-D$, so that Eq. (B6) simplifies to

$$
\frac{\partial Q_{i}^{j}}{\partial t}=\int_{m_{k}^{-}}^{m_{k}^{+}} \int_{f_{g_{1}^{(c-1)}}^{-}}^{f_{g_{1}^{(c-1)}}^{+}} \bar{n} I_{g_{i}} \mathrm{~d} m \mathrm{~d} f_{g_{1}^{(c-1)}}=N^{j} I_{g_{i}} .
$$

Thus, in each section, the change with time of number and mass concentrations is given by Eqs. (B4) and (B7). 


\section{Code availability}

The SCRAM source code related to this article is available under the URL http://cerea.enpc.fr/polyphemus/src/scram-1. 0. tar.gz, as a supplement package together with a Read Me file, where hardware and software requirements, source code files and model output files are fully described.

SCRAM is free software. You can redistribute it and/or modify it under the terms of the GNU General Public License as published by the Free Software Foundation.

Acknowledgements. The authors gratefully acknowledge $\mathrm{H}$. Dergaoui (INRA) for providing his original code of coagulation process and E. Debry (INERIS) for optimising the computation of coagulation distribution coefficients. We also would like to thank F. Couvidat (INERIS) for his support on the implementation of his $\mathrm{H}^{2} \mathrm{O}$ model into SCRAM as well as S. Deschamps (CEREA), who helped to improve the size redistribution algorithm.

Edited by: G. A. Folberth

\section{References}

Bauer, S. E., Wright, D. L., Koch, D., Lewis, E. R., McGraw, R., Chang, L.-S., Schwartz, S. E., and Ruedy, R.: MATRIX (Multiconfiguration Aerosol TRacker of mIXing state): an aerosol microphysical module for global atmospheric models, Atmos. Chem. Phys., 8, 6003-6035, doi:10.5194/acp-8-60032008, 2008.

Binkowski, F. S. and Roselle, S. J.: Models-3 Community Multiscale Air Quality (CMAQ) model aerosol component 1. Model description, J. Geophys. Res.-Atmos., 108, 4183, doi:10.1029/2001JD001409, 2003.

Capaldo, K., Pilinis, C., and Pandis, S. N.: A computationally efficient hybrid approach for dynamic gas/aerosol transfer in air quality models, Atmos. Environ., 34, 3617-3627, 2000.

Couvidat, F., Debry, É., Sartelet, K., and Seigneur, C.: A hydrophilic/hydrophobic organic (H2O) aerosol model: Development, evaluation and sensitivity analysis, J. Geophys. Res.Atmos., 117, D10304, doi:10.1029/2011JD017214, 2012.

Couvidat, F., Kim, Y., Sartelet, K., Seigneur, C., Marchand, N., and Sciare, J.: Modeling secondary organic aerosol in an urban area: application to Paris, France, Atmos. Chem. Phys., 13, 983-996, doi:10.5194/acp-13-983-2013, 2013.

Dahneke, B.: Simple kinetic theory of Brownian diffusion in vapors and aerosols, in: Theory of Dispersed Multiphase Flow, 97-133, Academic Press, 1983.

Deboudt, K., Flament, P., Choël, M., Gloter, A., Sobanska, S., and Colliex, C.: Mixing state of aerosols and direct observation of carbonaceous and marine coatings on African dust by individual particle analysis, J. Geophys. Res.-Atmos., 115, D24207, doi:10.1029/2010JD013921, 2010.

Debry, E. and Sportisse, B.: Reduction of the condensation/evaporation dynamics for atmospheric aerosols: Theoretical and numerical investigation of hybrid methods, J. Aerosol Sci., 37, 950-966, 2006.
Debry, E., Fahey, K., Sartelet, K., Sportisse, B., and Tombette, M.: Technical Note: A new SIze REsolved Aerosol Model (SIREAM), Atmos. Chem. Phys., 7, 1537-1547, doi:10.5194/acp-7-1537-2007, 2007.

Dergaoui, H., Sartelet, K. N., Debry, É., and Seigneur, C.: Modeling coagulation of externally mixed particles: Sectional approach for both size and chemical composition, J. Aerosol Sci., 58, 17-32, 2013.

Devilliers, M., Debry, É., Sartelet, K., and Seigneur, C.: A new algorithm to solve condensation/evaporation for ultra fine, fine, and coarse particles, J. Aerosol Sci., 55, 116-136, 2013.

Djouad, R., Sportisse, B., and Audiffren, N.: Numerical simulation of aqueous-phase atmospheric models: use of a non-autonomous Rosenbrock method, Atmos. Environ., 36, 873-879, 2002.

EPA, D.: Integrated science assessment for particulate matter, US Environmental Protection Agency Washington, DC, 2009.

Gelbard, F. and Seinfeld, J. H.: Simulation of multicomponent aerosol dynamics, J. Coll. Int. Sci., 78, 485-501, 1980.

Healy, R. M., Sciare, J., Poulain, L., Kamili, K., Merkel, M., Müller, T., Wiedensohler, A., Eckhardt, S., Stohl, A., Sarda-Estève, R., McGillicuddy, E., O'Connor, I. P., Sodeau, J. R., and Wenger, J. C.: Sources and mixing state of size-resolved elemental carbon particles in a European megacity: Paris, Atmos. Chem. Phys., 12, 1681-1700, doi:10.5194/acp-12-1681-2012, 2012.

Hughes, L. S., Allen, J. O., Bhave, P., Kleeman, M. J., Cass, G. R., Liu, D.-Y., Fergenson, D. P., Morrical, B. D., and Prather, K. A.: Evolution of atmospheric particles along trajectories crossing the Los Angeles basin, Environ. Sci. Technol., 34, 3058-3068, 2000.

Jacobson, M.: Analysis of aerosol interactions with numerical techniques for solving coagulation, nucleation, condensation, dissolution, and reversible chemistry among multiple size distributions, J. Geophys. Res., 107, 1327-1338, 2002.

Jacobson, M. Z.: Development and application of a new air pollution modeling system - II. Aerosol module structure and design, Atmos. Environ., 31, 131-144, 1997.

Jacobson, M. Z.: Strong radiative heating due to the mixing state of black carbon in atmospheric aerosols, Nature, 409, 695-697, 2001.

Jacobson, M. Z., Turco, R. P., Jensen, E. J., and Toon, O. B.: Modeling coagulation among particles of different composition and size, Atmos. Environ., 28, 1327-1338, 1994.

Kleeman, M. J. and Cass, G. R.: A 3D Eulerian source-oriented model for an externally mixed aerosol, Environ. Sci. Technol., 35, 4834-4848, 2001

Kleeman, M. J., Cass, G. R., and Eldering, A.: Modeling the airborne particle complex as a source-oriented external mixture, J. Geophys. Res.-Atmos., 102, 21355-21372, 1997.

Leck, C. and Svensson, E.: Importance of aerosol composition and mixing state for cloud droplet activation over the Arctic pack ice in summer, Atmos. Chem. Phys., 15, 2545-2568, doi:10.5194/acp-15-2545-2015, 2015.

Lesins, G., Chylek, P., and Lohmann, U.: A study of internal and external mixing scenarios and its effect on aerosol optical properties and direct radiative forcing, J. Geophys. Res.-Atmos., 107, AAC-5, 2002.

Lu, J. and Bowman, F. M.: A detailed aerosol mixing state model for investigating interactions between mixing state, semivolatile partitioning, and coagulation, Atmos. Chem. Phys., 10, 40334046, doi:10.5194/acp-10-4033-2010, 2010. 
Mallet, M., Roger, J., Despiau, S., Putaud, J., and Dubovik, O.: A study of the mixing state of black carbon in urban zone, J. Geophys. Res.-Atmos., 109, D04202, doi:10.1029/2003JD003940, 2004.

McMurry, P. H.: A review of atmospheric aerosol measurements, Atmos. Environ., 34, 1959-1999, 2000.

Myhre, G., Samset, B. H., Schulz, M., Balkanski, Y., Bauer, S., Berntsen, T. K., Bian, H., Bellouin, N., Chin, M., Diehl, T., Easter, R. C., Feichter, J., Ghan, S. J., Hauglustaine, D., Iversen, T., Kinne, S., Kirkevåg, A., Lamarque, J.-F., Lin, G., Liu, X., Lund, M. T., Luo, G., Ma, X., van Noije, T., Penner, J. E., Rasch, P. J., Ruiz, A., Seland, Ø., Skeie, R. B., Stier, P., Takemura, T., Tsigaridis, K., Wang, P., Wang, Z., Xu, L., Yu, H., Yu, F., Yoon, J.-H., Zhang, K., Zhang, H., and Zhou, C.: Radiative forcing of the direct aerosol effect from AeroCom Phase II simulations, Atmos. Chem. Phys., 13, 1853-1877, doi:10.5194/acp-13-18532013, 2013.

Nenes, A., Pandis, S. N., and Pilinis, C.: ISORROPIA: A new thermodynamic equilibrium model for multiphase multicomponent inorganic aerosols, Aqua. Geochem., 4, 123-152, 1998.

Oshima, N., Koike, M., Zhang, Y., Kondo, Y., Moteki, N., Takegawa, N., and Miyazaki, Y.: Aging of black carbon in outflow from anthropogenic sources using a mixing state resolved model: Model development and evaluation, J. Geophys. Res.Atmos., 114, D06210, doi:10.1029/2008JD010680, 2009.

Pandis, S. N., Wexler, A. S., and Seinfeld, J. H.: Secondary organic aerosol formation and transport - II. Predicting the ambient secondary organic aerosol size distribution, Atmos. Environ., 27, 2403-2416, 1993.

Pascal, M., Corso, M., Chanel, O., Declercq, C., Badaloni, C., Cesaroni, G., Henschel, S., Meister, K., Haluza, D., Martin-Olmedo, P., Medinaa, S. and on behalf of the Aphekom group: Assessing the public health impacts of urban air pollution in 25 European cities: Results of the Aphekom project, Sci. Total Environ., 449, 390-400, doi:10.1016/j.scitotenv.2013.01.077, 2013.

Pilinis, C., Capaldo, K., Nenes, A., and Pandis, S.: MADM-A new multicomponent aerosol dynamics model, Aerosol Sci. Technol., 32, 482-502, 2000.

Riemer, N., West, M., Zaveri, R. A., and Easter, R. C.: Simulating the evolution of soot mixing state with a particleresolved aerosol model, J. Geophys. Res., 114, D09202, doi:10.1029/2008JD011073, 2009.
Sartelet, K., Debry, E., Fahey, K., Roustan, Y., Tombette, M., and Sportisse, B.: Simulation of aerosols and gas-phase species over Europe with the Polyphemus system: Part I Model-to-data comparison for 2001, Atmos. Environ., 41, 6116-6131, 2007.

Seigneur, C., Hudischewskyj, A. B., Seinfeld, J. H., Whitby, K. T., Whitby, E. R., Brock, J. R., and Barnes, H. M.: Simulation of Aerosol Dynamics: A Comparative Review of Mathematical Models, Aerosol Sci. Technol., 5, 205-222, 1986.

Stier, P., Feichter, J., Kinne, S., Kloster, S., Vignati, E., Wilson, J., Ganzeveld, L., Tegen, I., Werner, M., Balkanski, Y., Schulz, M., Boucher, O., Minikin, A., and Petzold, A.: The aerosol-climate model ECHAM5-HAM, Atmos. Chem. Phys., 5, 1125-1156, doi:10.5194/acp-5-1125-2005, 2005.

Vehkamäki, H., Kulmala, M., Napari, I., Lehtinen, K. E., Timmreck, C., Noppel, M., and Laaksonen, A.: An improved parameterization for sulfuric acid-water nucleation rates for tropospheric and stratospheric conditions, J. Geophys. Res.-Atmos., 107, 9330, doi:10.1029/2002JD002184, 2002.

Verwer, J. G., Spee, E., Blom, J., and Hundsdorfer, W.: A secondorder Rosenbrock method applied to photochemical dispersion problems, SIAM J. Sci. Comput., 20, 1456-1480, 1999.

Wexler, A. S. and Seinfeld, J. H.: The distribution of ammonium salts among a size and composition dispersed aerosol, Atmos. Environ., 24, 1231-1246, 1990.

Whitby, E. R. and McMurry, P. H.: Modal aerosol dynamics modeling, Aerosol Sci. Technol., 27, 673-688, 1997.

Zhang, Y., Seigneur, C., Seinfeld, J. H., Jacobson, M. Z., and Binkowski, F. S.: Simulation of Aerosol Dynamics: A Comparative Review of Algorithms Used in Air Quality Models, Aerosol Sci. Technol., 31, 487-514, 1999.

Zhang, Y., Pun, B., Vijayaraghavan, K., Wu, S.-Y., Seigneur, C., Pandis, S. N., Jacobson, M. Z., Nenes, A., and Seinfeld, J. H.: Development and application of the model of aerosol dynamics, reaction, ionization, and dissolution (MADRID), J. Geophys Res.-Atmos., 109, D01202, doi:10.1029/2003JD003501, 2004.

Zhang, Y., McMurry, P. H., Yu, F., and Jacobson, M. Z.: A comparative study of nucleation parameterizations: 1 . Examination and evaluation of the formulations, J. Geophys. Res.-Atmos., 115, D20212, doi:10.1029/2010JD014150, 2010. 